\title{
THE CENTRAL LIMIT THEOREM FOR EUCLIDEAN MINIMAL SPANNING TREES I
}

\section{By SungChul LeE}

\section{National University of Singapore}

Let $\left\{X_{i}: i \geq 1\right\}$ be i.i.d. with uniform distribution $\left[-\frac{1}{2}, \frac{1}{2}\right]^{d}, d \geq 2$, and let $T_{n}$ be a minimal spanning tree on $\left\{X_{1}, \ldots, X_{n}\right\}$. For each strictly positive integer $\alpha$, let $\mathrm{N}\left(\left\{\mathrm{X}_{1}, \ldots, \mathrm{X}_{\mathrm{n}}\right\} ; \alpha\right)$ be the number of vertices of degree $\alpha$ in $\mathrm{T}_{\mathrm{n}}$. Then, for each $\alpha$ such that $\mathrm{P}\left(\mathrm{N}\left(\left\{\mathrm{X}_{1}, \ldots, \mathrm{X}_{\alpha+1}\right\} ; \alpha\right)=1\right)$ $>0$, we prove a central limit theorem for $\mathrm{N}\left(\left\{\mathrm{X}_{1}, \ldots, \mathrm{X}_{\mathrm{n}}\right\} ; \alpha\right)$.

1. Introduction. Let $\left\{X_{1}, \ldots, X_{n}\right\}$ be a finite subset of $R^{d}, d \geq 2$. A minimal spanning tree (MST) on $\left\{X_{1}, \ldots, X_{n}\right\}$ is a spanning tree $T\left(\left\{X_{1}, \ldots\right.\right.$, $\left.\left.X_{n}\right\}\right)$ on $\left\{X_{1}, \ldots, X_{n}\right\}$ such that

$$
\sum_{\mathrm{e} \in \mathrm{T}\left(\left\{\mathrm{X}_{1}, \ldots, \mathrm{X}_{n}\right\}\right)}|\mathrm{e}|=\min \left\{\sum_{\mathrm{e} \in \mathrm{T}}|\mathrm{e}|: \mathrm{T} \text { a spanning tree on }\left\{\mathrm{X}_{1}, \ldots, \mathrm{X}_{n}\right\}\right\},
$$

where $|e|=\left|X_{i}-X_{j}\right|$ is the Euclidean length of the edge $e=\left(X_{i}, X_{j}\right)$.

For applications of minimal spanning trees in computer science, see Whitney (1972), J ung (1974), Chang, Chang, Kang and Lee (1977), Bentley and Friedman (1978), Chin and Houck (1978) and Katajainen (1983). For applications of minimal spanning trees in physics, chemistry and biology, see Mallion (1975), Romane (1977), Wu (1977), Penny (1980), and Dussert et al. (1987). For applications of minimal spanning trees in statistics, see Rohlf (1975) and Friedman and Rafsky (1979, 1983).

Here are two problems considered in connection with a minimal spanning tree. The first problem is on the length of a minimal spanning tree. The second is on the number of vertices of a given degree $\alpha$ in a minimal spanning tree. Denote the length of a minimal spanning tree on $\left\{X_{1}, \ldots, X_{n}\right\}$ by

$$
\mathrm{L}\left(\left\{\mathrm{X}_{1}, \ldots, \mathrm{X}_{\mathrm{n}}\right\}\right):=\sum_{\mathrm{e} \in \mathrm{T}\left(\left\{\mathrm{X}_{1}, \ldots, \mathrm{X}_{n}\right\}\right)}|\mathrm{e}|
$$

and denote the number of vertices of a given degree $\alpha$ in a minimal spanning tree on $\left\{\mathrm{X}_{1}, \ldots, \mathrm{X}_{\mathrm{n}}\right\}$ by

$$
\mathrm{N}\left(\left\{\mathrm{X}_{1}, \ldots, \mathrm{X}_{\mathrm{n}}\right\} ; \alpha\right):=\mid\left\{\mathrm{X}_{\mathrm{i}} \text { : the degree of } \mathrm{X}_{\mathrm{i}} \text { in } \mathrm{T}\left(\left\{\mathrm{X}_{1}, \ldots, \mathrm{X}_{\mathrm{n}}\right\}\right) \text { is } \alpha\right\} \mid \text {. }
$$

Received J anuary 1996; revised March 1997.

AMS 1991 subject classifications. Primary 60D05, 60F 05; secondary 60K 35, 05C05, $90 \mathrm{C} 27$.

Key words and phrases. Minimal spanning tree, central limit theorem, continuum percolation. 
If $\left\{X_{i}: i \geq L\right\}$ are i.i.d. with uniform distribution on $\left[-\frac{1}{2}, \frac{1}{2}\right]^{d}, d \geq 2$, then Steele (1988) showed that, as $n \rightarrow \infty$,

$$
\frac{L\left(\left\{X_{1}, \ldots, X_{n}\right\}\right)}{n^{(d-1) / d}} \rightarrow \beta(d) \text { a.S., }
$$

and Eddy, Shepp and Steele (1987) showed that, as $n \rightarrow \infty$,

$$
\frac{\mathrm{N}\left(\left\{\mathrm{X}_{1}, \ldots, \mathrm{X}_{\mathrm{n}}\right\} ; \alpha\right)}{\mathrm{n}} \rightarrow \beta(\alpha, \mathrm{d}) \quad \text { a.s., }
$$

where $\beta(d)$ is a strictly positive but finite constant which depends only on the dimension $\mathrm{d}$ and where $\beta(\alpha, \mathrm{d})$ is a finite constant which depends only on the given degree $\alpha$ and the dimension $\mathrm{d}$. For related results, see Rhee and Talagrand (1989), Aldous and Steele (1992), Redmond and Yukich (1994) and Penrose (1996).

A central limit theorem associated with (1.1) has been proved independently by Alexander (1996) and by Kesten and Lee (1996). In this paper, we prove a central limit theorem associated with (1.2) which was conjectured by Eddy, Shepp and Steele (1987). Our basic idea is the same as that of Kesten and Lee (1996). Let $P_{1}(n)$ be a Poisson point process of density $n\left[-\frac{1}{2}, \frac{1}{2}\right]^{d}$. We represent $\mathrm{N}\left(\mathrm{P}_{1}(\mathrm{n}) ; \alpha\right)-\mathrm{EN}\left(\mathrm{P}_{1}(\mathrm{n}) ; \alpha\right)$ as a sum of martingale differences and we apply Lévy's martingale central limit theorem to the sum of martingale differences. In this way, the proof of the central limit theorem for $\mathrm{N}\left(\mathrm{P}_{1}(\mathrm{n}) ; \alpha\right)$ is reduced to a kind of weak law of large numbers estimate for certain conditional variances. Even though a weak law of large numbers is much easier to obtain, in general, than a central limit theorem, it still requires some independence. The required independence is obtained by approximating the conditional variances by quantities which depend only locally on the $P_{1}(n)$. This approximation is done by the stabilization property (Proposition 1) of minimal spanning trees. Loosely speaking, the stabilization property says that the minimal spanning tree structure is locally determined. Our first result is as follows:

THEOREM 1. Let $P_{1}(n)$ bea Poisson point process of density $n$ on $\left[-\frac{1}{2}, \frac{1}{2}\right]^{d}$, $\mathrm{d} \geq 2$. Then, for each strictly positive integer $\alpha$ such that $\mathrm{P}\left(\mathrm{N}\left(\mathrm{P}{ }_{1}(1) ; \alpha\right)=1\right)$ $>0$, as $\mathrm{n} \rightarrow \infty$,

$$
\frac{\mathrm{N}\left(\mathrm{P}_{1}(\mathrm{n}) ; \alpha\right)-\mathrm{EN}\left(\mathrm{P}_{1}(\mathrm{n}) ; \alpha\right)}{\mathrm{n}^{1 / 2}} \rightarrow \mathrm{N}\left(0, \tilde{\sigma}^{2}(\alpha, \mathrm{d})\right)
$$

in distribution for some $0<\tilde{\sigma}^{2}(\alpha, \mathrm{d})<\infty$.

We de-Poissonize Theorem 1 . That is, we replace a Poisson point process $P_{1}(n)$ of density $n$ on $\left[-\frac{1}{2}, \frac{1}{2}\right]^{d}$ with the $n$ i.i.d. uniform points $\left\{X_{1}, \ldots, X_{n}\right\}$ on $\left[-\frac{1}{2}, \frac{1}{2}\right]^{d}$ in Theorem 1 . Our second result is as follows. 
THEOREM 2. Let $\left\{X_{i}: i \geq 1\right\}$ bei.i.d. with uniform distribution on $\left[-\frac{1}{2}, \frac{1}{2}\right]^{d}$, $\mathrm{d} \geq 2$. Then, for each strictly positive integer $\alpha$ such that $\mathrm{P}\left(\mathrm{N}\left(\mathrm{P}_{1}(1) ; \alpha\right)=1\right)$ $>0$, as $\mathrm{n} \rightarrow \infty$,

$$
\frac{\mathrm{N}\left(\left\{\mathrm{X}_{1}, \ldots, \mathrm{X}_{\mathrm{n}}\right\} ; \alpha\right)-\mathrm{EN}\left(\left\{\mathrm{X}_{1}, \ldots, \mathrm{X}_{\mathrm{n}}\right\} ; \alpha\right)}{\mathrm{n}^{1 / 2}} \rightarrow \mathrm{N}\left(0, \sigma^{2}(\alpha, \mathrm{d})\right)
$$

in distribution for some $0<\sigma^{2}(\alpha, \mathrm{d})<\infty$.

In Section 2, we review minimal spanning trees and continuum percolation. By studying minimal spanning trees with the help of continuum percolation, we establish the stabilization property of minimal spanning trees. In Section 3, we prove Theorem 1. In Section 4, we de-Poissonize Theorem 1 and prove Theorem 2.

We would like to close the Introduction with a remark on the stabilization property of minimal spanning trees which we establish in this paper. This stabilization property is much stronger than the monotonicity property of minimal spanning trees which is essential to the argument of Kesten and Lee (1996): Kesten and Lee (1996) prove the central limit theorem for the length

$$
\mathrm{L}_{\psi}\left(\left\{\mathrm{X}_{1}, \ldots, \mathrm{X}_{\mathrm{n}}\right\}\right):=\sum_{\mathrm{e} \in \mathrm{T}\left(\left\{\mathrm{X}_{1}, \ldots, \mathrm{X}_{\mathrm{n}}\right\}\right)} \psi(|\mathrm{e}|)
$$

of a minimal spanning tree on $\left\{X_{1}, \ldots, X_{n}\right\}$, where, for a given function $\psi$, the weight on the edge e is given by $\psi(|\mathrm{e}|)$. Their central limit theorem holds with no continuity assumption on $\psi$. [Please, ignore the continuity assumption on $\psi$ just before Lemma 12 of Kesten and Lee (1996). It is a typo.] They prove Lemma 10 of Kesten and Lee (1996) only for $\psi(\mathrm{y})=\psi_{\alpha}(\mathrm{y})=\mathrm{y}^{\alpha}$. However, the lemma holds for the general $\psi$ as stated in the lemma. The full proof of the lemma is now available. The proof is based on the stabilization property, not the monotonicity property. Actually, one can adapt our argument to prove the central limit theorem of Kesten and Lee (1996). In fact, in the coming paper we establish the "strong" stabilization property of minimal spanning trees and we generalize the central limit theorems of Kesten and Lee (1996) and of this paper to the nonuniform sample points.

In this paper, there are many strictly positive but finite constants whose specific values are not of interest to us. We denote them by $C_{i}, C_{(q)}$ or $D_{d}$.

2. Stabilization of minimal spanning trees. In this section, we recall three algorithms for the construction of an MST: Kruskal's al gorithm, the add and delete algorithm, and the revised add and delete algorithm. We also review continuum percolation. By studying the structure of minimal spanning trees with the help of the revised add and delete algorithm and continuum percolation, we establish the stabilization property (Proposition 1) of minimal spanning trees.

Let us review minimal spanning trees first. Let $G=(V, E, w)$ be a connected weighted graph with vertex set $V$, edge set $E$ and weight function w: $\mathrm{E} \rightarrow[0, \infty)$. Assume that the cardinalities $|\mathrm{V}|,|\mathrm{E}|$ of $\mathrm{V}, \mathrm{E}$, respectively, are 
finite. A minimal spanning tree on $G$ is a tree $T$ with vertex set $V$ (so $T$ is a spanning tree on $V$ ) and edge set $E^{\prime} \subset E$ (which we express by $T \subset E$ for brevity) such that

$$
\sum_{e \in T} w(e)=\min \left\{\sum_{e \in T^{\prime}} w(e): T^{\prime} \text { a spanning tree on } V^{\prime}, T^{\prime} \subset E\right\} .
$$

Denote

$$
w(T):=\sum_{e \in T} w(e) .
$$

A minimal spanning tree $T$ on $G$ can be constructed by the following greedy algorithm due to Kruskal (1956).

KRUSKAL'S ALGORITHM.

Step 1. Let $T_{0}=\varnothing$ and let $E_{0}=\{e \in E:\{e\}$ is not a circuit $\}$.

Step 2. Once $T_{i}$ and $E_{i}$ have been determined, choose an edge $e_{i+1} \in E_{i}$ such that $w\left(e_{i+1}\right)=\min _{e \in E_{i}} w(e)$ and construct $T_{i+1}$ by adding the edge $e_{+1}$ to $T_{i}$. That is, define

$$
\mathrm{T}_{\mathrm{i}+1}=\mathrm{T}_{\mathrm{i}} \cup\left\{\mathrm{e}_{\mathrm{i}+1}\right\}
$$

Then, define

$$
E_{i+1}=\left\{e \in E_{i} \backslash\left\{e_{+1}\right\}: T_{i+1} \cup\{e\} \text { does not contain a circuit }\right\} .
$$

If there exists no such edge $e_{i+1}$, that is, if $E_{i}=\varnothing$, then define $T=T_{i}$ and stop.

Step 3. Replace i by $\mathrm{i}+1$. Return to Step 2 .

Let $G=(V, E, w)$ be a connected weighted graph with $|\mathrm{V}|<\infty,|\mathrm{E}|<\infty$, and let $\mathrm{G}^{\prime}=\left(\mathrm{V}^{\prime}, \mathrm{E}^{\prime}, \mathrm{w}^{\prime}\right)$ be another connected weighted graph with $\mathrm{V}^{\prime} \supset \mathrm{V}$, $\left|V^{\prime}\right|<\infty, E^{\prime} \supset E,\left|E^{\prime}\right|<\infty$. We assume that $w^{\prime}(e)=w(e)$ for all $e \in E$ so that $\mathbf{w}^{\prime}$ is an extension of $\mathbf{w}$. We therefore drop the prime from $\mathbf{w}^{\prime}$ in the sequel and we denote the weight function on $\mathrm{G}^{\prime}$ also by $\mathrm{w}$.

Now, let T be an MST on G. We would like to construct an MST T' on G'. We may, of course, construct an MST $\mathrm{T}^{\prime}$ by directly applying Kruskal's algorithm to the graph G'. However, this algorithm is not efficient in this case, because this does not use the fact that T is already an MST on G. We propose here the add and delete algorithm and the revised add and delete algorithm for the construction of an MST $\mathrm{T}^{\prime}$ on $\mathrm{G}^{\prime}$ : The original add and delete algorithm was proposed by Kesten and Lee (1996) and the add and delete algorithm below is slightly generalized from the original one [this algorithm was already studied by Chin and Houck (1978)]. However, proof needs no change. The revised add and delete algorithm is revised from the add and delete algorithm to handle the situation if we have the additional information that some edges $e \in E^{\prime} \backslash E$ do not belong to any MST $T^{\prime}$ on $G^{\prime}$. The proof is given in Lemma 2 below. 
ADD AND DELETE ALGORITHM.

Step 1. Let $T_{0}=T$ and let $E^{\prime} \backslash E=\left\{e_{1}, \ldots, e_{1}\right\}$.

Step 2. Once $T_{i}$ has been determined, add $e_{i+1}$ to $T_{i}$. That is, form $\mathrm{T}_{\mathrm{i}} \cup\left\{\mathrm{e}_{\mathrm{i}+1}\right\}$. If $\mathrm{T}_{\mathrm{i}} \cup\left\{\mathrm{e}_{\mathrm{i}+1}\right\}$ does not contain a circuit, define

$$
\mathrm{T}_{\mathrm{i}+1}=\mathrm{T}_{\mathrm{i}} \cup\left\{\mathrm{e}_{\mathrm{i}+1}\right\} \text {. }
$$

Otherwise, $T_{i} \cup\left\{e_{+1}\right\}$ contains a unique circuit $C_{i+1}$. Choose $f_{i+1} \in C_{i+1}$ such that $w\left(f_{i+1}\right)=\max _{e \in C_{i+1}} w(e)$, and define

$$
\mathrm{T}_{\mathrm{i}+1}=\mathrm{T}_{\mathrm{i}} \cup\left\{\mathrm{e}_{\mathrm{i}+1}\right\} \backslash\left\{\mathrm{f}_{\mathrm{i}+1}\right\} \text {. }
$$

If there is no such edge $e_{+1}$, that is, if $i=I$, then define $T^{\prime}=T_{1}$ and stop.

Step 3. Replace i by $\mathrm{i}+1$. Return to Step 2.

ReVISED ADD AND DELeTE ALgorithm. Apply the add and delete algorithm to $\left(E^{\prime} \backslash E\right) \backslash E^{\prime \prime}$ instead of $E^{\prime} \backslash E$ if no edge e of $E^{\prime \prime}\left(\subset E^{\prime} \backslash E\right)$ belongs to any MST $\mathrm{T}^{\prime}$ on $\mathrm{G}^{\prime}$.

The next three lemmas are simple facts on the add and delete algorithm and the revised add and delete algorithm.

Lemma 1. Let $T$ be an MST on $G=(V, E, w),|V|<\infty,|E|<\infty$, and let $T^{\prime}$ be an MST on $\mathrm{G}^{\prime}=\left(\mathrm{V}^{\prime}, \mathrm{E}^{\prime}, \mathrm{w}\right), \mathrm{V}^{\prime} \supset \mathrm{V},\left|\mathrm{V}^{\prime}\right|<\infty, \mathrm{E}^{\prime} \supset \mathrm{E},\left|\mathrm{E}^{\prime}\right|<\infty$, constructed by applying the add and delete algorithm with $E^{\prime} \backslash E=\left\{e_{1}, \ldots, e\right\}$ to an MST $\mathrm{T}$ on $\mathrm{G}$. Then

$$
T^{\prime} \subset\left(T \cup\left\{e_{1}, \ldots, e_{1}\right\}\right)
$$

and

$$
\left(T^{\prime} \cap E\right) \subset T \text {. }
$$

Moreover, for $\mathrm{V}^{\prime \prime} \subset \mathrm{V}$ with $\mathrm{V}^{\prime \prime} \cap\left\{\mathrm{x}:(\mathrm{x}, \mathrm{y}) \in\left\{\mathrm{e}_{1}, \ldots, \mathrm{e}_{1}\right\}\right.$ for some $\left.\mathrm{y}\right\}=\varnothing$,

$$
\left\{(\mathrm{x}, \mathrm{y}) \in \mathrm{T}^{\prime}: \mathrm{x} \in \mathrm{V}^{\prime \prime}\right\} \subset\left\{(\mathrm{x}, \mathrm{y}) \in \mathrm{T}: \mathrm{x} \in \mathrm{V}^{\prime \prime}\right\} \text {. }
$$

Proof. The lemma follows immediately from the add and delete algorithm. We leave this as a simple exercise for the reader.

Lemma 2. Let $G=(V, E, w)$ be a connected weighted graph with $|V|<\infty$, $|E|<\infty$, and let $G^{\prime}=\left(V^{\prime}, E^{\prime}, w\right)$ be another connected weighted graph with $V^{\prime} \supset V,\left|V^{\prime}\right|<\infty, E^{\prime} \supset E,\left|E^{\prime}\right|<\infty$. Assume that any edge $e \in E^{\prime \prime}\left(\subset E^{\prime} \backslash E\right)$ does not belong to any MST $T^{\prime}$ on $\mathrm{G}^{\prime}$. Let $T$ be an MST on $G$ and let $T^{\prime \prime}$ be a spanning tree on $\mathrm{V}^{\prime}$ constructed by applying the add and delete algorithm with $\left(E^{\prime} \backslash E\right) \backslash E^{\prime \prime}$ to an MST T on G. Then $T^{\prime \prime}$ is still an MST on $G^{\prime}$.

Proof. Define a connected weighted graph $G^{\prime \prime}$ by $G^{\prime \prime}=\left(V^{\prime}, E^{\prime} \backslash E^{\prime \prime}, w\right)$. Since an MST $T^{\prime}$ on $G^{\prime}$ does not contain any edge $e \in E^{\prime \prime}, T^{\prime}$ is a subgraph of $\mathrm{G}^{\prime \prime}$ and hence $\mathrm{G}^{\prime \prime}$ is indeed connected. Since $\mathrm{T}^{\prime}$ is a spanning tree on $\mathrm{V}^{\prime}$ in $\mathrm{G}^{\prime \prime}$, for an MST $T^{\prime \prime}$ on $G^{\prime \prime}$ we have $w\left(T^{\prime \prime}\right) \leq w\left(T^{\prime}\right)$. So, for any spanning tree $T^{\prime \prime \prime}$ on $V^{\prime}$ in $G^{\prime}$ we have $w\left(T^{\prime \prime}\right) \leq w\left(T^{\prime}\right) \leq w\left(T^{\prime \prime \prime}\right)$, because $T^{\prime}$ is an MST on $G^{\prime}$. 
Hence an MST $\mathrm{T}^{\prime \prime}$ on $\mathrm{G}^{\prime \prime}$ is an MST on $\mathrm{G}^{\prime}$. In particular, a spanning tree $\mathrm{T}^{\prime \prime}$ on $V^{\prime}$ constructed by applying the add and delete algorithm with $\left(E^{\prime} \backslash E\right) \backslash E^{\prime \prime}$ to an MST T on G is an MST on G" and hence an MST on $\mathrm{G}^{\prime}$.

LEMmA 3. Let $G=(V, E, w)$ be a connected weighted graph with $|V|<\infty$, $|E|<\infty$, and let $G^{\prime}=\left(V^{\prime}, E^{\prime}, w\right)$ be another connected weighted graph with $V^{\prime} \supset V,\left|V^{\prime}\right|<\infty, E^{\prime} \supset E,\left|E^{\prime}\right|<\infty$. Denote $E^{\prime} \backslash E=\left\{e_{1}, \ldots, e_{1}\right\}$. Let $T$ be an MST on $G$ and, for each $0 \leq i \leq 1$, let $T_{i}$ be the ith subset of $E^{\prime}$ constructed by applying the add and delete al gorithm with $\left\{\mathrm{e}_{1}, \ldots, \mathrm{e}_{\mathrm{i}}\right\}$ to an MST T on G ( see Step 2 of the add and detete al gorithm). Let $C$ be a connected component of $T_{i}$. Then the restriction $T_{i} \cap C$ of $T_{i}$ to $C$ is an $M S T$ on $G_{i}(C)=\left(V_{i}(C), E_{i}(C)\right.$, w), where $V_{i}(C)=\left\{x:(x, y) \in E_{i}(C)\right.$ for some $\left.y\right\}$ and where $E_{i}(C)$ is the connected component of $E \cup\left\{e_{1}, \ldots, e_{i}\right\}$ containing $C$.

Proof. If $E_{i}(C)$ contains a given MST $T$ on $G$, then $T_{i} \cap C$ is the tree constructed by applying the add and del ete algorithm with $\left\{e_{1}, \ldots, e_{i}\right\} \cap E_{i}(C)$ to an MST T on G. So, $T_{i} \cap C$ is an MST on $G_{i}(C)$. If $E_{i}(C)$ does not contain $T$, then there exists the first edge $e_{j}=(u, v), 1 \leq j \leq i$, such that $e_{j} \in E_{i}(C)$. Then $T_{i} \cap C$ is the tree constructed by applying the add and del ete algorithm with $\left\{e_{1}, \ldots, e_{i}\right\} \cap E_{i}(C)$ to an MST $\left\{e_{j}\right\}$ on $\left(\{u, v\},\left\{e_{j}\right\}, w\right)$. So, $T_{i} \cap C$ is again an MST on $\mathrm{G}_{\mathrm{i}}(\mathrm{C})$.

Now we collect two basic facts on an MST.

Lemma 4. Let $\mathrm{G}=(\mathrm{V}, \mathrm{E}, \mathrm{w})$ be a connected weighted graph with $|\mathrm{V}|<\infty$, $|E|<\infty$. If there exists a path $\pi=\left(e_{1}, \ldots, e_{n}\right)$ in $G$ from $v_{1} \in V$ to $v_{2} \in V$ such that $\mathrm{w}\left(\mathrm{e}_{1}\right) \leq \lambda, 1 \leq \mathrm{i} \leq \mathrm{n}$, then for any MST $\mathrm{T}$ on $\mathrm{G}$ there exists a path $\pi^{\prime}=\left(e_{1}^{\prime}, \ldots, e_{m}^{\prime}\right)$ in $T$ from $v_{1}$ to $v_{2}$ such that $w\left(e_{j}^{\prime}\right) \leq \lambda, 1 \leq \mathrm{j} \leq \mathrm{m}$.

Proof. See Kesten and Lee [(1996), Lemma 2].

Lemma 5. Let $G=(V, E, w)$ be a connected weighted graph with $|V|<\infty$, $|E|<\infty$. Assume that, for $e_{1} \neq e_{2} \in E$,

$$
w\left(e_{1}\right) \neq w\left(e_{2}\right) \text {. }
$$

Then there exists a unique MST T on G.

Proof. See Rosen [(1995), Exercise 8.6.19]. The answer is provided there.

Let a finite subset $A$ of $R^{d}, d \geq 2$, be given. Construct a connected weighted graph $G=(V, E, w)$ from $A$ in the following way: $V:=A, E:=$ $\{(\mathrm{x}, \mathrm{y}): \mathrm{x} \neq \mathrm{y} \in \mathrm{V}\}$ and $\mathrm{w}((\mathrm{x}, \mathrm{y})):=|\mathrm{x}-\mathrm{y}|$, where $|\mathrm{x}-\mathrm{y}|$ is the Euclidean distance between $x$ and $y$. So, it is reasonable to think of the edge $(x, y)$ as the line segment between $x$ and $y$. If $G$ satisfies (2.5), then by Lemma 5 there exists a unique MST T ( A ) on G [we sometimes call T ( A ) an MST on A instead]. All the $\mathrm{G}$ (or rather A) of interest satisfy (2.5) with probability 1. 
From now on, we assume all the finite sets A of interest satisfy (2.5) so that an MST T(A) on A is unique We also assume all the infinite sets $W$ of interest are locally finite. These assumptions hold with probability 1 .

Denote $T(A)$ a minimal spanning tree on $A$ and $T^{(0)}(A)$ a minimal spanning tree on $A \backslash\left[-\frac{1}{2}, \frac{1}{2}\right]^{d}$. If $A$ is a Poisson point process $P_{n}$ of density 1 on $\left[-n^{1 / d} / 2, n^{1 / d} / 2\right]^{d}$, then denote by $\tilde{T}_{n}$ a minimal spanning tree on $P_{n}$ and by $\tilde{T}_{n}^{(0)}$ a minimal spanning tree on $P_{n} \backslash\left[-\frac{1}{2}, \frac{1}{2}\right]^{d}$. If $A$ is $n$ i.i.d. uniform points $\left\{X_{1}^{(n)}, \ldots, X_{n}^{(n)}\right\}$ on $\left[-n^{1 / d} / 2, n^{1 / d} / 2\right]^{d}$, then denote by $T_{n}$ a minimal spanning tree on $\left\{X_{1}^{(n)}, \ldots, X_{n}^{(n)}\right\}$ and by $T_{n}^{(0)}$ a minimal spanning tree on $\left\{X_{1}^{(n)}, \ldots, X_{n}^{(n)}\right\} \backslash\left[-\frac{1}{2}, \frac{1}{2}\right]^{d}$. So, $\tilde{T}_{n}=T\left(P_{n}\right), \tilde{T}_{n}^{(0)}=T\left(P_{n} \backslash\left[-\frac{1}{2}, \frac{1}{2}\right]^{d}\right), T_{n}=$ $T\left(\left\{X_{1}^{(n)}, \ldots, X_{n}^{(n)}\right\}\right)$ and $T_{n}^{(0)}=T\left(\left\{X_{1}^{(n)}, \ldots, X_{n}^{(n)}\right\} \backslash\left[-\frac{1}{2}, \frac{1}{2}\right]^{d}\right)$.

If we apply the add and delete algorithm with $\left\{\mathrm{e}_{1}, \ldots, \mathrm{e}_{1}\right\}$ to $\mathrm{T}(\mathrm{A})$ $\left[T^{(0)}(A), \tilde{T}_{n}, \tilde{T}_{n}^{(0)}, T_{n}, T_{n}^{(0)}\right.$, respectively], we denote the $i$ th graph constructed by $T_{i}(A)\left[T_{i}^{(0)}(A), \tilde{T}_{n, i}, \tilde{T}_{n, i}^{(0)}, T_{n, i}, T_{n, i}^{(0)}\right.$, respectively] (see Step 2 of the add and delete algorithm).

Define, for a finite subset $\mathrm{A}$ of $\mathrm{R}^{\mathrm{d}}$ and for a strictly positive integer $\alpha$,

$$
\mathrm{N}(\mathrm{A} ; \alpha)=\mid\{\mathrm{x} \text { : the degree of } \mathrm{x} \text { in an MST T }(\mathrm{A}) \text { on } \mathrm{A} \text { is } \alpha\} \mid \text {. }
$$

Define further, for a finite subset $A$ of $R^{d}$ and a subset $B$ of $R^{d}$, and for $a$ strictly positive integer $\alpha$,

$$
\begin{aligned}
& \{e(A, B)\}=\{e: e \in T(A), e \notin T(A \backslash B)\}, \\
& \{f(A, B)\}=\{f: f \notin T(A), f \in T(A \backslash B)\}
\end{aligned}
$$

and

$$
\mathrm{D}(\mathrm{A}, \mathrm{B} ; \alpha)=\mathrm{N}(\mathrm{A} ; \alpha)-\mathrm{N}(\mathrm{A} \backslash \mathrm{B} ; \alpha) .
$$

Let $G=(V, E, w)$ be the graph induced by a set $A ;\left(v_{1}, e_{1}, v_{2}, e_{2}, \ldots, e_{n}\right.$, $v_{n+1}$ ) is a path from $v_{1}$ to $v_{n+1}$ in $G$ (or rather in $A$ ) if $v_{i} \in V, 1 \leq i \leq n+1$, and $e_{j}=\left(v_{j}, v_{j+1}\right) \in E, 1 \leq j \leq n$. We sometimes denote the path $\left(v_{1}, e_{1}, v_{2}\right.$, $\left.e_{2}, \ldots, e_{n}, v_{n+1}\right)$ by $\left(v_{1}, v_{2}, \ldots, v_{n+1}\right)$ or $\left(e_{1}, e_{2}, \ldots, e_{n}\right)$. A path $\left(v_{1}, v_{2}, \ldots, v_{n+1}\right)$ is self-avoiding if $v_{i} \neq v_{j}$ for $i \neq j$.

Let $Q_{n}$ be the d-dimensional cube of volume $n$ of the form

$$
Q_{n}=\left[-n^{1 / d} / 2, n^{1 / d} / 2\right]^{d}
$$

For $x=\left(x_{1}, \ldots, x_{d}\right), y=\left(y_{1}, \ldots, y_{d}\right) \in R^{d}$ and for $I, L>0$, define

$$
\begin{aligned}
B[x, y] & =\prod_{i=1}^{d}\left[x_{i}, y_{i}\right], \\
Q(x) & =\prod_{i=1}^{d}\left[x_{i},-\frac{1}{2}, x_{i}+\frac{1}{2}\right] \\
A(B[x, y] ; I, L) & =\prod_{i=1}^{d}\left[x_{i}-I-L, y_{i}+I+L\right] \backslash \prod_{i=1}^{d}\left(x_{i}-I, y_{i}+I\right) .
\end{aligned}
$$


We call $\mathrm{B}[\mathrm{x}, \mathrm{y}], \mathrm{Q}(\mathrm{x})$ and $\mathrm{A}(\mathrm{B}[\mathrm{x}, \mathrm{y}] ; \mathrm{I}, \mathrm{L})$ a rectangle, a cube and an annulus, respectively.

DEFINITION 1. Let $\delta>0$. A blocking set of width $\delta$ for the rectangle $\mathrm{B}[\mathrm{x}, \mathrm{y}]$ is a finite set $\mathrm{S}$ in the annulus $\mathrm{A}(\mathrm{B}[\mathrm{x}, \mathrm{y}] ; 1, \delta)$ with the following property: each line segment from $\partial \Pi\left[\mathrm{x}_{\mathrm{i}}-1, \mathrm{y}_{\mathrm{i}}+1\right]$ to $\partial \Pi\left[\mathrm{x}_{\mathrm{i}}-1-\delta, \mathrm{y}_{\mathrm{i}}+\right.$ $1+\delta$ ] passes within distance $\frac{1}{3}$ of some point of $S$ [see Kesten and Lee (1996), Figure 2].

Most of the time, the vertices of interest lie in $Q_{n}=\left[-n^{1 / d} / 2, n^{1 / d} / 2\right]^{d}$. Thus, the edges of interest also lie in $Q_{n}$. In these cases, it is useful to relax the above definition.

Definition 2. Let $\delta>0$. An n-blocking set of width $\delta$ for the rectangle $\mathrm{B}[\mathrm{x}, \mathrm{y}]$ is a finite set $S$ in $\mathrm{A}(\mathrm{B}[\mathrm{x}, \mathrm{y}] ; 1, \delta) \cap \mathrm{Q}_{\mathrm{n}}$ with the following property: each line segment from $\left(\partial \Pi\left[x_{i}-1, y_{i}+1\right]\right) \cap Q_{n}$ to $\left(\partial \Pi\left[x_{i}-1-\delta, y_{i}+\right.\right.$ $1+\delta]) \cap Q_{n}$ passes within distance $\frac{1}{3}$ of some point of $S$.

The reader should note that, if $\left(\partial \Pi\left[\mathrm{x}_{\mathrm{i}}-1-\delta, \mathrm{y}_{\mathrm{i}}+1+\delta\right]\right) \cap \mathrm{Q}_{\mathrm{n}}=\varnothing$, then $\varnothing$ is an $\mathrm{n}$-blocking set.

The term "blocking set" is justified by the next lemma. However, here we would like to point out that, even if there exists a blocking set, the existence of a blocking set does not imply the kind of independence one may wish to have: the next lemma just says that, if there is a blocking set, some long edges are not in an MST. It does not say that, if there is a blocking set, some short edges are in an MST.

Lemma 6. Let $S$ be a blocking set of width $\delta$ for the rectangle $B[\mathrm{x}, \mathrm{y}]$. Then, in any MST T(A) on the graph $G=(V, E, w)$ induced by $A, A \supset S$, there are no edges between vertices in $B[x, y]$ and vertices in $R^{d} \backslash \Pi\left(x_{i}-2-\right.$ $\left.\delta, \mathrm{y}_{\mathrm{i}}+2+\delta\right)$. This still holds for any MST on the graph $\mathrm{G}^{\prime}=\left(\mathrm{V}, \mathrm{E}^{\prime}, \mathrm{w}\right)$, $E^{\prime} \subset E, G^{\prime}$ connected, if $\{(x, y): x \in S, y \in A, x \neq y\} \subset E^{\prime}$. The same result holds for an $n$-blocking set if $A \subset Q_{n}$.

Proof. The proof is the same as that of Lemma 3 of Kesten and Lee (1996).

Denote the set of the Poisson points of density 1 in $R^{d}$ by $P$. If we are only interested in the Poisson points in $Q_{n}$, denote the set of the Poisson points in $Q_{n}$ by $P_{n}$. Thus $P_{n}=P \cap Q_{n}$.

We also choose $m$ i.i.d. uniform points on $Q_{n}$ Denote these random points by $X_{1}^{(n)}, \ldots, X_{m}^{(n)}$ and the set of these random points by $U_{n}(m)$. In the case $m=n$, we simplify the notation $U_{n}(m)$ to $U_{n}$. 
The next two lemmas are about the existence of a blocking set.

Lemma 7. There exist constants $0<\mathrm{C}_{1}, \mathrm{C}_{2}<\infty$ such that, for $\mathrm{B}[\mathrm{x}, \mathrm{y}]$,

$\mathrm{P}$ (thereis no blocking set $\mathrm{S}$ of width $\delta$ of $\mathrm{P}$-points

for the rectangle $\mathrm{B}[\mathrm{x}, \mathrm{y}]$ in theannulus $\mathrm{A}(\mathrm{B}[\mathrm{x}, \mathrm{y}] ; 1, \delta))$

$$
\leq \mathrm{C}_{1} \gamma^{2(\mathrm{~d}-1)} \exp \left(-\mathrm{C}_{2} \delta\right),
$$

where $\gamma=\left[\sum\left(\mathrm{y}_{\mathrm{i}}-\mathrm{x}_{\mathrm{i}}+2+2 \delta\right)^{2}\right]^{1 / 2}$ is the diameter of the rectangle $\Pi\left[\mathrm{x}_{\mathrm{i}}-\right.$ $\left.1-\delta, \mathrm{y}_{\mathrm{i}}+1+\delta\right]$. Moreover, (2.10) holds with the term "blocking set" re placed by "n-blocking set."

Proof. See Kesten and Lee [(1996), Lemma 5].

Lemma 8. There exist constants $0<\mathrm{C}_{1}, \mathrm{C}_{2}, \mathrm{C}_{3}, \mathrm{C}_{4}<\infty$ such that, for $3 n / 4 \leq m \leq 5 n / 4$ and for $B[x, y]$,

$$
\begin{aligned}
& \mathrm{P}\left(\text { there is no n-blocking set } \mathrm{S} \text { of width } \delta \text { of } \mathrm{U}_{\mathrm{n}}(\mathrm{m})\right. \text {-points } \\
& \text { for the rectangle } \mathrm{B}[\mathrm{x}, \mathrm{y}] \text { in theannulus } \mathrm{A}(\mathrm{B}[\mathrm{x}, \mathrm{y}] ; 1, \delta)) \\
& \quad \leq \mathrm{C}_{1} \gamma^{2(\mathrm{~d}-1)} \exp \left(-\mathrm{C}_{2} \delta\right)+\mathrm{C}_{3} \exp \left(-\mathrm{C}_{4} \mathrm{n}\right)
\end{aligned}
$$

where, as in Lemma 7, $\gamma=\left[\Sigma\left(y_{i}-x_{i}+2+2 \delta\right)^{2}\right]^{1 / 2}$ is the diameter of the rectangle $\Pi\left[\mathrm{x}_{\mathrm{i}}-1-\delta, \mathrm{y}_{\mathrm{i}}+1+\delta\right]$.

Proof. See Kesten and Lee [(1996), Lemma 6].

Now, we review continuum percolation. F or a set $W$ of points in $\mathrm{R}^{\mathrm{d}}$ and for $r \geq 0$, define

$$
C(r ; W)=\bigcup_{x \in W}\left\{y \in R^{d}:|x-y| \leq r\right\} .
$$

In the case $W=P$, we simplify the notation $C(r ; P)$ to $C(r)$.

Denote the event that $C(r ; W)$ has an unbounded connected component which contains $x$ by $\left\{x \leftrightarrow_{r} \infty\right.$ in $\left.W\right\}$. Then, $U_{X \in R^{d}}\left\{X \leftrightarrow_{r} \infty\right.$ in $\left.W\right\}$ is the event that $\mathrm{C}(\mathrm{r} ; \mathrm{W})$ has an unbounded connected component. The fundamental theorem of continuum percolation says that there exists a constant $0<r_{c}=$ $r_{c}(d)<\infty$ such that

$$
P\left(0 \leftrightarrow_{r} \infty \text { in } P\right) \begin{cases}>0, & \text { if } r>r_{c}, \\ =0, & \text { if } r<r_{c} .\end{cases}
$$

Since $U_{X \in R^{d}}\left\{x \leftrightarrow_{r} \infty\right.$ in $\left.P\right\}$ is in the tail $\sigma$-field, $P\left(0 \leftrightarrow_{r} \infty\right.$ in $\left.P\right)>0$ implies $P\left(U_{X \in R}\left\{x \leftrightarrow_{r} \infty\right.\right.$ in $\left.\left.P\right\}\right)=1$. So, for $r>r_{C}, C(r)$ has an unbounded connected component with probability 1 and, for $r<r_{c}, C(r)$ has no unbounded connected component with probability 1 . If $\mathrm{C}(r)$ has an unbounded connected 
component, then actually $\mathrm{C}(\mathrm{r})$ has exactly one unbounded connected component. More strongly, the uniqueness of an unbounded connected component of $C(r)$ holds simultaneously, that is,

$$
\begin{aligned}
& \mathrm{P} \text { (for each } r \geq 0, C(r) \text { has at most } \\
& \quad \text { one unbounded connected component })=1 \text {. }
\end{aligned}
$$

See Alexander (1995) for details.

If $\mathrm{C}(\mathrm{r}$; $\mathrm{W})$ has exactly one unbounded connected component, then denote the unique unbounded connected component of $C(r ; W)$ by $C_{\infty}(r ; W)$. In the case $W=P$, we again simplify $C_{\infty}(r ; P)$ by $C_{\infty}(r)$.

The next lemma is a simple corollary to (2.12).

Lemma 9. Let $D$ bea fixed measurablesubset of $R^{d}, d \geq 2$, with $m(D)<\infty$, where $m$ is the Lebesgue measure on $R^{d}$. Then

$$
\begin{aligned}
& P \text { ( for each } r \geq 0, C(r ; P \backslash D) \text { has at most } \\
& \quad \text { one unbounded connected component })=1 .
\end{aligned}
$$

Proof. Since $\mathrm{m}(\mathrm{D})<\infty, \mathrm{P}(\mathrm{P} \cap \mathrm{D}=\varnothing)>0$. So, by (2.12),

$P$ (for each $r \geq 0, C(r)$ has at most one unbounded connected component $\mid \mathrm{P} \cap \mathrm{D}=\varnothing)=1$.

Therefore, since $P \backslash D$ and $P \cap D$ are independent, (2.13) follows.

We still need more notation. For a finite set $W$ of points in $\mathrm{R}^{\mathrm{d}}$, define

$$
\begin{aligned}
\left\{\tilde{\mathrm{e}}_{\mathrm{L}}(\mathrm{x} ; \mathrm{W})\right\} & =\left\{\mathrm{e}\left(\Pi\left[\mathrm{x}_{\mathrm{i}}-\mathrm{L}, \mathrm{x}_{\mathrm{i}}+\mathrm{L}\right] \cap \mathrm{W}, \mathrm{Q}(\mathrm{x})\right)\right\}, \\
\left\{\tilde{\mathrm{f}}_{\mathrm{L}}(\mathrm{x} ; \mathrm{W})\right\} & =\left\{\mathrm{f}\left(\Pi\left[\mathrm{x}_{\mathrm{i}}-\mathrm{L}, \mathrm{x}_{\mathrm{i}}+\mathrm{L}\right] \cap \mathrm{W}, \mathrm{Q}(\mathrm{x})\right)\right\}, \\
\tilde{\mathrm{D}}_{\mathrm{L}}(\mathrm{x} ; \mathrm{W}, \alpha) & =\mathrm{D}\left(\Pi\left[\mathrm{x}_{\mathrm{i}}-\mathrm{L}, \mathrm{x}_{\mathrm{i}}+\mathrm{L}\right] \cap \mathrm{W}, \mathrm{Q}(\mathrm{x}) ; \alpha\right)
\end{aligned}
$$

and

$$
\mathrm{D}_{\mathrm{L}}(\mathrm{x} ; \mathrm{W} \cup\{\mathrm{x}\}, \alpha)=\mathrm{D}\left(\Pi\left[\mathrm{x}_{\mathrm{i}}-\mathrm{L}, \mathrm{x}_{\mathrm{i}}+\mathrm{L}\right] \cap(\mathrm{W} \cup\{\mathrm{x}\}),\{\mathrm{x}\} ; \alpha\right) .
$$

We shall approximate $\mathrm{D}(\mathrm{W}, \mathrm{Q}(\mathrm{x}) ; \alpha)$ and $\mathrm{D}(\mathrm{W} \cup\{\mathrm{x}\},\{\mathrm{x}\} ; \alpha)$ by $\tilde{\mathrm{D}}_{\mathrm{L}}(\mathrm{x} ; \mathrm{W}, \alpha)$ and $D_{L}(x ; W \cup\{x\}, \alpha)$, respectively.

The next proposition is the stabilization property of minimal spanning trees, which is the main result of this section.

PROPOSITION 1. There exists a random variable $0<\mathrm{L}_{1}=\mathrm{L}_{1}(\mathrm{P})<\infty$ such that with probability 1 , for $B=B[x, y] \supset\left[-L_{1}, L_{1}\right]^{d}$,

$$
\begin{aligned}
\{e(P \cap B, Q(0))\} & =\left\{\tilde{e}_{L_{1}}(0 ; P)\right\}, \\
\{f(P \cap B, Q(0))\} & =\left\{\tilde{f}_{L_{1}}(0 ; P)\right\}, \\
D(P \cap B, Q(0) ; \alpha) & =\tilde{D}_{L_{1}}(0 ; P) .
\end{aligned}
$$


Also, there exists another random variable $0<L_{2}=L_{2}(P \cup\{0\})<\infty$ such that with probability 1 , for $B=B[x, y] \supset\left[-L_{2}, L_{2}\right]^{d}$,

$$
\mathrm{D}((\mathrm{P} \cap \mathrm{B}) \cup\{0\},\{0\} ; \alpha)=\mathrm{D}_{\mathrm{L}_{2}}(0 ; \mathrm{P} \cup\{0\}, \alpha) .
$$

Proof. We prove here (2.18)-(2.20). The same argument works for (2.21). By Lemma 7, we can choose a finite random $\mathrm{N}_{1}$ such that there is a blocking set $S$ of width $N_{1}$ of $P$-points for the cube $Q(0)$ in the annulus $A\left(Q(0) ; 1, N_{1}\right)$. For $\mathrm{n}$ with

$$
\mathrm{Q}_{\mathrm{n}} \supset\left(-\frac{5}{2}-\mathrm{N}_{1}, \frac{5}{2}+\mathrm{N}_{1}\right)^{\mathrm{d}} \text {, }
$$

we can construct an MST $\tilde{T}_{n+1}$ on $P_{n+1}$ by applying the revised add and delete algorithm with the edges e in $\tilde{T}_{n+1} \backslash \tilde{T}_{n}$ to an MST $\tilde{T}_{n}$ on $P_{n}$. Since, by Lemma 6 , there are no edges in $\tilde{T}_{n+1}$ between points $x \in Q_{n+1} \backslash Q_{n}$ and points $\mathrm{y} \in \mathrm{Q}(0)$, it follows from the revised add and delete al gorithm that the set $\left\{(x, y) \in \tilde{T}_{n}: x \in Q(0)\right\}$ of edges incident to points $x \in P_{1}$ in $\tilde{T}_{n}$ is eventually decreasing in $n$. That is, for large $n$,

$$
\left\{(\mathrm{x}, \mathrm{y}) \in \tilde{\mathrm{T}}_{\mathrm{n}+1}: \mathrm{x} \in \mathrm{Q}(0)\right\} \subset\left\{(\mathrm{x}, \mathrm{y}) \in \tilde{\mathrm{T}}_{\mathrm{n}}: \mathrm{x} \in \mathrm{Q}(0)\right\} .
$$

Therefore, we can choose a finite random $N_{2}$ such that, for $n \geq N_{2}$,

$$
\left\{(\mathrm{x}, \mathrm{y}) \in \tilde{\mathrm{T}}_{\mathrm{n}}: \mathrm{x} \in \mathrm{Q}(0)\right\}=\left\{(\mathrm{x}, \mathrm{y}) \in \tilde{\mathrm{T}}_{\mathrm{N}_{2}}: \mathrm{x} \in \mathrm{Q}(0)\right\} \text {. }
$$

This proves (2.18) for all $B$ of the form $Q_{n}$.

Now, we will prove (2.19) for all $B$ of the form $Q_{n}$. This somewhat long argument is based on the simultaneous uniqueness of infinite clusters, that is, Lemma 9. Let

$$
\left\{e_{i}=\left(x_{i}, y_{i}\right): 1 \leq i \leq l\right\}=\left\{(x, y) \in \tilde{T}_{N_{2}}: x \in Q(0)\right\}
$$

be the set of edges incident to points $x \in P_{1}$ in $\tilde{T}_{N_{2}}$. From now on, let $n \geq N_{2}$.

We compare $\tilde{T}_{n}^{(0)}$ and $\tilde{T}_{n}$. After constructing an $\mathrm{MST}_{\mathrm{T}} \tilde{T}_{n}^{(0)}$ on $\mathrm{P}_{n} \backslash \mathrm{Q}(0)$, we apply the revised add and delete algorithm with $\left\{\mathrm{e}_{1}: 1 \leq \mathrm{i} \leq \mathrm{I}\right\}$ to $\tilde{T}_{n}^{(0)}$. By (2.23) and (2.24), this yields an MST $\tilde{T}_{n}$ on $P_{n}$. We need to describe this second stage more explicitly. Let $\tilde{T}_{n, 0}^{(0)}=\tilde{T}_{n}^{(0)}$. Once $\tilde{T}_{n, i}^{(0)}$ has been determined, form $\tilde{T}_{n, i}^{(0)} \cup\left\{e_{i+1}\right\}$. If $\tilde{T}_{n, i}^{(0)} \cup\left\{e_{i+1}\right\}$ does not contain a circuit, define $\tilde{T}_{n, i+1}^{(0)}=$ $\tilde{T}_{n, i}^{(0)} \cup\left\{e_{i+1}\right\}$. Otherwise, $\tilde{T}_{n, i}^{(0)} \cup\left\{e_{i+1}\right\}$ contains a unique circuit $C_{n, i+1}$. Choose $f_{n, i+1}=\left(u_{n, i+1}, v_{n, i+1}\right) \in C_{n, i+1}$ such that $\left|f_{n, i+1}\right|=\max _{e \in C_{n, i+1}}|e|$. Define $\tilde{T}_{n, i+1}^{(0)}=\tilde{T}_{n, i}^{(0)} \cup\left\{e_{+1}\right\} \backslash\left\{f_{n, i+1}\right\}$. Then, as we saw above,

$$
\tilde{\mathrm{T}}_{\mathrm{n}}=\tilde{\mathrm{T}}_{\mathrm{n}, 1}^{(0)} \text {. }
$$

We claim that with probability 1 , for each $1 \leq i \leq 1, f_{n, i}$ changes only finitely many times; that is,

$$
\left|\bigcup_{n \geq N_{2}}\left\{f_{n, i}\right\}\right|<\infty .
$$


To derive a contradiction, let us assume that, for some i,

$$
\left|\bigcup_{n \geq N_{2}}\left\{f_{n, i}\right\}\right|=\infty \text {. }
$$

Then, $\tilde{T}_{n, i-1}^{(0)} \cup\left\{e_{i}\right\}$ contains a unique circuit $C_{n, i}$, and $f_{n, i} \in C_{n, i}$ satisfies

$$
\left|f_{n, i}\right|=\max _{e \in C_{n, i}}|e|
$$

Note that, for large $n$,

$$
f_{n, i} \neq e_{i}
$$

because otherwise e would be deleted and not be an edge in $\tilde{T}_{n, i}^{(0)}$, nor in $\tilde{T}_{n, 1}^{(0)}=\tilde{T}_{n}$, and this contradicts (2.23) and (2.24); $\tilde{T}_{n+1, i-1}^{(0)} \cup\left\{e_{i}\right\}$ also contains a unique circuit $C_{n+1, i}$, and $f_{n+1, i} \in C_{n+1, i}$ satisfies $\left|f_{n+1, i}\right|=\max _{e \in C_{n+1, i}}|e|$. However, there is a path $\pi=\left(g_{1}, \ldots, g_{m_{1}}\right)$ from one end $x_{i}$ of $e_{i}$ to the other end $y_{i}$ of $e_{i}$ in $\tilde{T}_{n, i-1}^{(0)}$ (more specifically in $C_{n, i} \backslash\left\{e_{i}\right\}$ ) such that, for $1 \leq k \leq m_{1}$,

$$
\left|g_{k}\right| \leq\left|f_{n, i}\right| \text {. }
$$

By Lemma 4 and Lemma 3, there then exists another path $\pi^{\prime}=\left(g_{1}^{\prime}, \ldots, g_{m_{2}}^{\prime}\right)$ from $x_{i}$ to $y_{i}$ in $\tilde{T}_{n+1, i+1}^{(0)}$ such that, for $1 \leq k \leq m_{2}$,

$$
\left|g_{k}^{\prime}\right| \leq\left|f_{n, i}\right| \text {. }
$$

In fact, this path $\pi^{\prime}$ is in $C_{n+1, i} \backslash\left\{e_{i}\right\}$ and hence contains $f_{n+1, i}$. By (2.27), we therefore have

(2.28)

$$
\left|f_{n+1, i}\right| \leq\left|f_{n, i}\right| .
$$

Now, let

$$
\left\{f_{n(j), i}: j \geq 1\right\}
$$

be an infinite subset of distinct edges from $U_{n \geq N_{2}}\left\{f_{n, i}\right\}$. Since $f_{n(j), i} \neq f_{n\left(j^{\prime}\right), i}$, $\mathrm{j} \neq \mathrm{j}^{\prime}$, by (2.28) we may assume that

$$
\left|f_{n(j+1), i}\right|<\left|f_{n(j), i}\right| .
$$

We next note that, with probability 1 ,

$$
\lim _{j \rightarrow \infty}\left|u_{n(j), i}\right| \wedge\left|v_{n(j), i}\right|=\infty .
$$

This follows from the fact that, for each $t \geq 0$, by Lemma 7 there exists with probability 1 a finite random $\mathrm{N}_{3}(\mathrm{t}) \geq \mathrm{N}_{2}$ such that

$$
P \cup\left(\left[-N_{3}(t), N_{3}(t)\right]^{d} \backslash[-t-1, t+1]^{d}\right)
$$

contains a blocking set for $[-t, t]^{d}$. By Lemma 6 and Lemma 3, there are then no edges in $\tilde{T}_{n, i-1}^{(0)}$ between $[-t, t]^{d}$ and the complement of $\left(-N_{3}(t)-\right.$ $\left.1, N_{3}(t)+1\right)^{d}$. Thus, there are only finitely many possibilities for edges $f_{n(j), i}$ with one endpoint in $[-t, t]^{d}$. Since this holds for each $t,(2.30)$ follows.

Now, let

$$
r_{i}:=\lim _{j \rightarrow \infty}\left|f_{n(j), i}\right| .
$$


By (2.29), this limit exists and, for each $\mathrm{j} \geq 1$,

$$
r_{i}<\left|f_{n(j), i}\right| \text {. }
$$

By the choice of $f_{n(j),}$, there exist two disjoint self-avoiding paths, $\pi_{n(j), i, 1}$ from one end $x_{i}$ of $e_{i}$ to one end $u_{n(j), i}$ of $f_{n(j), i}$ in $C_{n(j), i} \backslash\left\{e_{i}, f_{n(j), i}\right\}$, and $\pi_{n(j), i, 2}$ from the other end $y_{i}$ of $e_{i}$ to the other end $v_{n(j), i}$ of $f_{n(j), i}$ in $C_{n(j), i} \backslash\left\{e_{i}, f_{n(j), i}\right\}$. By (2.30), for large $j$,

$$
u_{n(j), i}, v_{n(j), i} \in R^{d} \backslash(-t, t)^{d} .
$$

If this is the case, then we can take initial pieces $\pi_{1}^{(\mathrm{t})}=\left(\mathrm{u}_{1,1}^{(\mathrm{t})}=\mathrm{x}_{\mathrm{i}}, \ldots, \mathrm{u}_{1}^{(\mathrm{t})} \mathrm{m}_{3}\right)$ of $\pi_{\mathrm{n}(\mathrm{j}), \mathrm{i}, 1}$, and $\pi_{2}^{(\mathrm{t})}=\left(\mathrm{u}_{2,1}^{(\mathrm{t})}=\mathrm{y}_{\mathrm{i}}, \ldots, \mathrm{u}_{2, \mathrm{~m}_{4}}^{(\mathrm{t})}\right)$ of $\pi_{\mathrm{n}(\mathrm{j}), \mathrm{i}, 2}$ such that

$$
\left|\mathrm{u}_{1, \mathrm{~m}_{3}}^{(\mathrm{t})}\right| \geq \mathrm{t} \text { but }\left|\mathrm{u}_{1, \mathrm{k}}^{(\mathrm{t})}\right|<\mathrm{t} \text { for } 1 \leq \mathrm{k}<\mathrm{m}_{3},
$$

and

$$
\left|\mathrm{u}_{2, \mathrm{~m}_{4}}^{(\mathrm{t})}\right| \geq \mathrm{t} \text { but }\left|\mathrm{u}_{2, \mathrm{k}}^{(\mathrm{t})}\right|<\mathrm{t} \text { for } 1 \leq \mathrm{k}<\mathrm{m}_{4} .
$$

Moreover, since $\pi_{\mathrm{n}(\mathrm{j}), \mathrm{i}, 1}$ and $\pi_{\mathrm{n}(\mathrm{j}), \mathrm{i}, 2}$ are disjoint and self-avoiding, so are their initial pieces $\pi_{1}^{(\mathrm{t})}$ and $\pi_{2}^{(\mathrm{t})}$. Finally, by virtue of (2.26), it holds that $\left|\left(u_{1, k}^{(t)}, u_{1, k+1}^{(t)}\right)\right| \leq\left|f_{n(j), i}\right|$ and hence for $1 \leq k<m_{3}$,

$$
\left|u_{1, k}^{(t)}-u_{1, k+1}^{(t)}\right| \leq\left|f_{n(j), i}\right| \text {. }
$$

Similarly, for $1 \leq \mathrm{k}<\mathrm{m}_{4}$,

$$
\left|u_{2, k}^{(t)}-u_{2, k+1}^{(t)}\right| \leq\left|f_{n(j), i}\right| .
$$

As above, there are only finitely many possibilities for the pair $\left(\pi_{1}^{(\mathrm{t})}, \pi_{2}^{(\mathrm{t})}\right)$. By a standard selection argument, we can therefore find a fixed pair $\left(\pi_{1}^{(\mathrm{t})}, \pi_{2}^{(\mathrm{t})}\right)$ which satisfies (2.33)-(2.36) for infinitely many j. By (2.31), (2.35) and (2.36), we then have

$$
\begin{array}{ll}
\left|u_{1, k}^{(t)}-u_{1, k+1}^{(t)}\right| \leq r_{i}, & 1 \leq k<m_{3}, \\
\left|u_{2, k}^{(t)}-u_{2, k+1}^{(t)}\right| \leq r_{i}, & 1 \leq k<m_{4} .
\end{array}
$$

Since $t$ can be chosen arbitrarily large, by (2.12) there exists a unique unbounded connected component $\mathrm{C}_{\infty}\left(\mathrm{r}_{\mathrm{i}} / 2\right)$ in $\mathrm{C}\left(\mathrm{r}_{\mathrm{i}} / 2\right)$. In addition,

$$
\mathrm{C}_{\infty}\left(\mathrm{r}_{\mathrm{i}} / 2\right) \cap\left[-\frac{1}{2}, \frac{1}{2}\right]^{\mathrm{d}} \neq \varnothing \text {. }
$$

Moreover, by (2.13) with $D=\left[-\frac{1}{2}, \frac{1}{2}\right]^{d}$, there exists a unique unbounded connected component $C_{\infty}\left(r_{i} / 2 ; P \backslash\left[-\frac{1}{2}, \frac{1}{2}\right]^{d}\right)$ in $C\left(r_{i} / 2 ; P \backslash\left[-\frac{1}{2}, \frac{1}{2}\right]^{d}\right)$ with

$$
C_{\infty}\left(r_{i} / 2 ; P \backslash\left[-\frac{1}{2}, \frac{1}{2}\right]^{d}\right) \cap[-M, M]^{d} \neq \varnothing \text {. }
$$

where

$$
M=\left\lceil\frac{1}{2}+r_{i} / 2\right\rceil
$$


The number of bounded connected components $C$ in $C\left(r_{i} / 2 ; P \backslash\left[-\frac{1}{2}, \frac{1}{2}\right]^{d}\right)$ with $C \cap[-M, M]^{d} \neq \varnothing$ is bounded by $\left|P \cap[-2 M, 2 M]^{d}\right|$. So

$$
\begin{aligned}
& \mathrm{R}_{1}:=\max \{|x|: x \in C, C \text { a bounded connected component } \\
& \text { in } C\left(r_{i} / 2 ; P \backslash\left[-\frac{1}{2}, \frac{1}{2}\right]^{d}\right) \\
&\text { with } \left.C \cap[-M, M]^{d} \neq \varnothing\right\}<\infty .
\end{aligned}
$$

Hence, for $t>R_{1}, u_{1}^{(t)} m_{3}$ and $u_{2, m_{4}}^{(t)}$ belong to the unique unbounded connected component $C_{\infty}\left(r_{i} / 2 ; P \backslash\left[-\frac{1}{2}, \frac{1}{2}\right]^{d}\right)$, because otherwise (by the simultaneous uniqueness of infinite clusters, i.e., Lemma 9) $u_{1, m_{3}}^{(t)}\left(\right.$ or $\left.u_{2,}^{(t)} m_{4}\right)$ would belong to a bounded connected component $C$ in $C\left(r_{i} / 2 ; P \backslash\left[-\frac{1}{2}, \frac{1}{2}\right]^{d}\right)$ with $C \cap$ $[-\mathrm{M}, \mathrm{M}]^{\mathrm{d}} \neq \varnothing, \mid \mathrm{u}_{1, \mathrm{~m}_{3}}^{(\mathrm{t})} \geq \mathrm{t}$, and this contradicts (2.37). Therefore, by concate nating $\pi_{1}^{(\mathrm{t})}$, a path from in $\mathrm{u}_{1, \mathrm{~m}_{3}}^{(\mathrm{t})}$ to $\mathrm{u}_{2, \mathrm{~m}_{4}}^{(\mathrm{t})}$ in $\mathrm{C}_{\infty}\left(\mathrm{r}_{\mathrm{i}} / 2\right.$; $\left.\mathrm{P} \backslash\left[-\frac{1}{2}, \frac{1}{2}\right]^{\mathrm{d}}\right)$, and $\pi_{2}^{(\mathrm{t})}$, there exists, for large $n$, a path $\pi=\left(h_{1}, \ldots, h_{m}\right)$ from $x_{i}$ to $y_{i}$ in $\{(x, y)$ : $\left.x \neq y \in P_{n} \backslash\left[-\frac{1}{2}, \frac{1}{2}\right]^{d}\right\} \cup\left\{e_{1}, \ldots, e_{i-1}\right\}$ such that, for $1 \leq k \leq m$,

$$
\left|h_{k}\right| \leq r_{i} \text {. }
$$

By Lemma 4 and Lemma 3 , then $f_{n, i}$ should satisfy

$$
\left|f_{n, i}\right| \leq r_{i} .
$$

This contradicts (2.32). Therefore, (2.25) indeed holds.

From here on, the proof is easy. Since $f_{n, i}$ changes only finitely many times, there exists, for each $1 \leq \mathrm{i} \leq \mathrm{I}$ such that $\left\{\mathrm{f}_{\mathrm{n}, \mathrm{i}}\right\} \neq \varnothing$ for all $\mathrm{n} \geq \mathrm{N}_{2}$, $N(i) \geq N_{2}$ such that, for $n \geq N(i)$,

$$
f_{n, i}=f_{N(i), i}
$$

In particular, for $\mathrm{n} \geq \mathrm{N}_{4}$,

$$
\tilde{T}_{n}^{(0)} \backslash \tilde{T}_{n}=\tilde{T}_{N_{4}}^{(0)} \backslash \tilde{T}_{N_{4}}
$$

where

$$
\mathrm{N}_{4}=\max \left\{\mathrm{N}(\mathrm{i}):\left\{\mathrm{f}_{\mathrm{n}, \mathrm{i}}\right\} \neq \varnothing \text { for all } \mathrm{n} \geq \mathrm{N}_{2}\right\} \vee \mathrm{N}_{2} .
$$

This proves (2.19) for all $B$ of the form $Q_{n}$.

Now, we use a simple squeezing argument to prove (2.18) and (2.19) for all $B$ of the general form $B[x, y]$. There exists a finite random $N_{5} \geq N_{4}$, by the argument for (2.23), such that, for $\mathrm{n} \geq \mathrm{N}_{5}$,

$$
\left\{(\mathrm{x}, \mathrm{y}) \in \tilde{\mathrm{T}}_{\mathrm{n}}^{(0)}: \mathrm{x} \in \mathrm{Q}_{\mathrm{N}_{4}}\right\}=\left\{(\mathrm{x}, \mathrm{y}) \in \tilde{\mathrm{T}}_{\mathrm{N}_{5}}^{(0)}: \mathrm{x} \in \mathrm{Q}_{\mathrm{N}_{4}}\right\},
$$

and, by enlarging $\mathrm{N}_{5}$ if necessary, such that

there exists a blocking set $S$ of width $\mathrm{N}_{5}^{1 / d} / 2-2-$ $\mathrm{N}_{4}^{1 / d} / 2$ of $P$-points for the rectangle $Q_{N_{4}}$ in the annulus $A\left(Q_{N_{4}} ; 1, N_{5}^{1 / d} / 2-2-N_{4}^{1 / d} / 2\right)$. 
Now, let

$$
\mathrm{L}_{1}:=\mathrm{L}_{1}(\mathrm{P})=\mathrm{N}_{5}^{1 / \mathrm{d}} / 2 .
$$

For general $B=B[x, y] \supset\left[-L_{1}, L_{1}\right]^{d}=Q_{N_{5}}$, we choose a finite $N_{6}$ such that

$$
\mathrm{Q}_{\mathrm{N}_{5}} \subset \mathrm{B} \subset \mathrm{Q}_{\mathrm{N}_{6}} \text {. }
$$

Then, exactly as in (2.22), one sees that, by (2.40),

$$
\{(x, y) \in T(P \cap B): x \in Q(0)\} \subset\left\{(x, y) \in \tilde{T}_{N_{5}}: x \in Q(0)\right\} .
$$

Similarly,

$$
\left\{(\mathrm{x}, \mathrm{y}) \in \tilde{\mathrm{T}}_{\mathrm{N}_{6}}: \mathrm{x} \in \mathrm{Q}(0)\right\} \subset\{(\mathrm{x}, \mathrm{y}) \in \mathrm{T}(\mathrm{P} \cap \mathrm{B}): \mathrm{x} \in \mathrm{Q}(0)\} .
$$

However, since $[$ by $(2.23)]\left\{(x, y) \in \tilde{T}_{N_{5}}: x \in Q(0)\right\}=\left\{(x, y) \in \tilde{T}_{N_{6}}: x \in Q(0)\right\}$, we have

$$
\{(x, y) \in T(P \cap B): x \in Q(0)\}=\left\{(x, y) \in \tilde{T}_{N_{5}}: x \in Q(0)\right\}
$$

This proves (2.18) for all $B$ of the general form $B[x, y]$ with $L_{1}$ given by (2.41).

By the argument for (2.42) and by (2.39) [instead of (2.23)], we have

$$
\left\{(x, y) \in T^{(0)}(P \cap B): x \in Q_{N_{4}}\right\}=\left\{(x, y) \in \tilde{T}_{N_{5}}^{(0)}: x \in Q_{N_{4}}\right\} \text {. }
$$

Then, exactly as in (2.28), one see that, for each $1 \leq \mathrm{i} \leq \mathrm{I}$ such that $\left\{\mathrm{f}_{\mathrm{n}, \mathrm{i}}\right\} \neq \varnothing$ for all $n \geq N_{2}$,

where

$$
\left|f_{N_{6}, i}\right| \leq\left|f_{i}(B)\right| \leq\left|f_{N_{5}, i}\right|
$$

$$
f_{i}(B) \in T_{i-1}^{(0)}(P \cap B) \backslash T_{i}^{(0)}(P \cap B) .
$$

From (2.38), we again find

$$
f_{i}(B)=f_{N_{5}, i} \text {. }
$$

This proves (2.19) for all $B$ of the general form $B[x, y]$ with $L_{1}$ given by (2.41).

Now, (2.20) follows from (2.42), (2.43) and (2.39).

3. Poissonization. In this section, by the stabilization property of minimal spanning trees, we prove Theorem 1. It is more natural for the proof to rescale the point process so that the density of the point set remains constant. So, actually we prove in this section that, for each strictly positive integer $\alpha$ such that $\mathrm{P}\left(\mathrm{N}\left(\mathrm{P}_{1}(1) ; \alpha\right)=1\right)>0$, as $\mathrm{n} \rightarrow \infty$,

$$
\frac{\mathrm{N}\left(\mathrm{P}_{\mathrm{n}} ; \alpha\right)-\mathrm{EN}\left(\mathrm{P}_{\mathrm{n}} ; \alpha\right)}{\mathrm{n}^{1 / 2}} \rightarrow \mathrm{N}\left(0, \tilde{\sigma}^{2}(\alpha, \mathrm{d})\right)
$$

in distribution for some $0<\tilde{\sigma}^{2}(\alpha, \mathrm{d})<\infty$.

The argument here is almost the same as that of Kesten and Lee (1996). So, we show the argument without proof since one can find it in Kesten and Lee (1996). 
We order the points of $Z^{d} \cap\left[-n^{1 / d} / 2-\frac{1}{2}, n^{1 / d} / 2+\frac{1}{2}\right]^{d}$ in some way, say lexicographically, as $v(1), \ldots, v(l)$, and we define $F_{k}$ by

$$
\mathrm{F}_{\mathrm{k}}=\sigma\left(\mathrm{P}_{\mathrm{n}} \cap\left[\bigcup_{\mathrm{i} \leq \mathrm{k}} \mathrm{Q}(\mathrm{V}(\mathrm{i}))\right]\right)
$$

( $\mathrm{F}_{0}$ is the trivial $\sigma$-field). Then $\mathrm{N}\left(\mathrm{P}_{n} ; \alpha\right)-\mathrm{EN}\left(\mathrm{P}_{n} ; \alpha\right)$ can be written as a sum of martingale differences. That is,

$$
\mathrm{N}\left(\mathrm{P}_{\mathrm{n}} ; \alpha\right)-\mathrm{EN}\left(\mathrm{P}_{\mathrm{n}} ; \alpha\right)=\sum_{\mathrm{k}=1}^{\mathrm{l}} \Delta_{\mathrm{k}},
$$

where [recall that we define $\mathrm{D}(\mathrm{A}, \mathrm{B} ; \alpha)$ in $(2.9)$ and $\tilde{\mathrm{D}}_{\mathrm{L}}(\mathrm{x} ; \mathrm{W}, \alpha)$ in (2.16)]

$$
\begin{aligned}
\Delta_{k}=E\left(N\left(P_{n} ; \alpha\right) \mid F_{k}\right)-E\left(N\left(P P_{n} ; \alpha\right) \mid F_{k-1}\right) \\
=\int P\left(d a_{k}, \ldots, d a_{l}\right)\left[N\left(\left[\bigcup_{i \leq k} A_{i}\right] \cup\left[\bigcup_{i>k} a_{i}\right] ; \alpha\right)\right. \\
\left.-N\left(\left[\bigcup_{i<k} A_{i}\right] \cup\left[\bigcup_{i \geq k} a_{i}\right] ; \alpha\right)\right] \\
=\int P\left(d a_{k}, \ldots, d a_{l}\right)\left[D\left(\left[\bigcup_{i \leq k} A_{i}\right] \cup\left[\bigcup_{i>k} a_{i}\right], A_{k} ; \alpha\right)\right. \\
\left.-D\left(\left[\bigcup_{i<k} A_{i}\right] \cup\left[\bigcup_{i \geq k} a_{i}\right], a_{k} ; \alpha\right)\right],
\end{aligned}
$$

and where $A_{i}=P_{n} \cap Q(v(i)), 1 \leq i \leq 1$, and $P\left(d a_{k}, \ldots, d a_{1}\right)$ is short for $P\left(A_{k} \in d a_{k}, \ldots, A_{1} \in d a_{1}\right)$.

Now we write $\Delta_{k, L}$ for the expression in (3.3) when $D\left(\left[U_{i \leq k} A_{i}\right] \cup\right.$ $\left.\left[U_{i>k} a_{i}\right], A_{k} ; \alpha\right)$ and $D\left(\left[\cup_{i<k} A_{i}\right] \cup\left[U_{i>k} a_{i}\right], a_{k} ; \alpha\right)$ are replaced by $D_{L}(v(k)$; $\left.\left[U_{i \leq k} A_{i}\right] \cup\left[U_{i>k} a_{i}\right], \alpha\right)$ and $\tilde{D}_{L}\left(v(k) ;\left[U_{i<k} A_{i}\right] \cup\left[U_{i \geq k} a_{i}\right], \alpha\right)$, respectively. That is,

$$
\begin{aligned}
\Delta_{k, L}=\int P\left(d a_{k}, \ldots, d a_{l}\right) & {\left[\tilde{D}_{L}\left(v(k) ;\left[\bigcup_{i \leq k} A_{i}\right] \cup\left[\bigcup_{i>k} a_{i}\right], \alpha\right)\right.} \\
& \left.-\tilde{D}_{L}\left(v(k) ;\left[\bigcup_{i<k} A_{i}\right] \cup\left[\bigcup_{i \geq k} a_{i}\right], \alpha\right)\right] .
\end{aligned}
$$

Note that $\Delta_{k}$ depends on $P_{n}$ whereas $\Delta_{k, L}$ depends only on $\Pi\left[(v(k))_{i}-\right.$ $\left.\mathrm{L},(\mathrm{V}(\mathrm{k}))_{\mathrm{i}}+\mathrm{L}\right] \cap \mathrm{P}_{\mathrm{n}}$.

By virtue of representation (3.2) of $\mathrm{N}\left(\mathrm{P}_{n} ; \alpha\right)-\mathrm{EN}\left(\mathrm{P}_{n} ; \alpha\right)$ as a sum of martingale differences and by Theorem 67.2 of Lévy (1937), Theorem (2.3) of McLeish (1974) or Theorem 3.2 of Hall and Heyde (1980), to prove (3.1) it suffices to verify the following three relations (3.5)-(3.7): there exists a 
constant, $0<\tau^{2}<\infty$ such that

$$
\begin{gathered}
\frac{1}{\mathrm{n}} \sum_{\mathrm{k}} \Delta_{\mathrm{k}}^{2} \rightarrow \tau^{2} \quad \text { in probability as } \mathrm{n} \rightarrow \infty, \\
\frac{1}{\mathrm{n}^{1 / 2}} \max _{\mathrm{k}}\left|\Delta_{\mathrm{k}}\right| \rightarrow 0 \quad \text { in probability as } \mathrm{n} \rightarrow \infty, \\
\frac{1}{\mathrm{n}} \mathrm{E}\left(\max _{\mathrm{k}} \Delta_{\mathrm{k}}^{2}\right) \text { is bounded in } \mathrm{n} .
\end{gathered}
$$

Relations (3.6) and (3.7) can be easily verified by Chebyshev's inequality and by the moment estimates in Lemma 11.

LEMma 10. There exists a finite constant $D_{d}$, which depends only on the dimension $d$, such that, for any MST T (A) on any finite subset A of $R^{d}, T(A)$ has maximum vertex degree bounded by $D_{d}$.

Proof. See Kesten and Lee [(1996), Lemma 4].

Lemma 11. For each $q>0$, there exists a constant $C_{(q)}$ such that

$$
\begin{array}{r}
\mathrm{E}\left|\tilde{\mathrm{D}}_{\mathrm{L}}(\mathrm{X} ; \mathrm{P}, \alpha)\right|^{q} \leq \mathrm{C}_{(\mathrm{q})} \quad \text { uniformly in } \mathrm{L}, \mathrm{x}, \alpha, \\
\mathrm{E}\left|\mathrm{D}_{\mathrm{L}}(\mathrm{X} ; \mathrm{P} \cup\{\mathrm{x}\}, \alpha)\right|^{q} \leq \mathrm{C}_{(\mathrm{q})} \text { uniformly in } \mathrm{L}, \mathrm{x}, \alpha, \\
\mathrm{E}\left|\tilde{\mathrm{D}}_{\mathrm{L}}\left(\mathrm{X}_{\mathrm{m}}^{(\mathrm{n})} ; \mathrm{U}_{\mathrm{n}}(\mathrm{m}), \alpha\right)\right|^{q} \leq \mathrm{C}_{(\mathrm{q})} \\
\quad \text { uniformly in } \mathrm{L}, \mathrm{n}, \frac{3 \mathrm{n}}{4} \leq \mathrm{m} \leq \frac{5 \mathrm{n}}{4}, \alpha, \\
\mathrm{E}\left|\mathrm{D}_{\mathrm{L}}\left(\mathrm{X}_{\mathrm{m}}^{(\mathrm{n})} ; \mathrm{U}_{\mathrm{n}}(\mathrm{m}), \alpha\right)\right|^{q} \leq \mathrm{C}_{(\mathrm{q})} \\
\quad \text { uniformly in } \mathrm{L}, \mathrm{n}, \frac{3 \mathrm{n}}{4} \leq \mathrm{m} \leq \frac{5 \mathrm{n}}{4}, \alpha .
\end{array}
$$

Proof. To have the moment estimate in (3.8), first we construct an MST $T(1)$ on $\left(\Pi\left[x_{i}-L, x_{i}+L\right] \backslash Q(x)\right) \cap P$. Second we construct an MST $T$ (2) on $\Pi\left[x_{i}-L, x_{i}+L\right] \cap P$ by applying the revised add and del ete al gorithm with $T(2) \backslash T(1)$ to $T(1)$. Since by Lemma 10 each $v \in Q(x) \cap P$ has degree bounded by $D_{d}$ in $T(2)$,

$$
|T(2) \backslash T(1)| \leq D_{d}|Q(x) \cap P| \text {. }
$$

So, it follows from the revised add and delete algorithm that

$$
\begin{aligned}
& \mid\left\{u \in\left(\Pi\left[x_{i}-L, x_{i}+L\right] \cap P\right) \backslash Q(x) \text { : the degree of } u \text { in } T(1)\right. \text { is not } \\
& \text { equal to the degree of } u \text { in } T(2)\} \mid \\
& \quad \leq D_{d}|Q(x) \cap P|,
\end{aligned}
$$


and hence that

$$
\left|\tilde{D}_{\mathrm{L}}(\mathrm{x} ; \mathrm{P}, \alpha)\right| \leq|\mathrm{Q}(\mathrm{x}) \cap \mathrm{P}|+\mathrm{D}_{\mathrm{d}}|\mathrm{Q}(\mathrm{x}) \cap \mathrm{P}| .
$$

Therefore, the moment estimate in (3.8) holds. The arguments for other moment estimates are the same.

So, the heart of the matter is the proof of (3.5). To prove (3.5), it suffices to verify the following three relations (3.13)-(3.15) [one can easily see why this is so on page 524 of Kesten and Lee (1996)]: for fixed L,

$$
\frac{1}{\mathrm{n}} \sum_{\mathrm{k}} \Delta_{\mathrm{k}, \mathrm{L}}^{2} \rightarrow \tau_{\mathrm{L}}^{2} \text { in probability as } \mathrm{n} \rightarrow \infty \text {, }
$$

where

$$
\begin{aligned}
\tau_{\mathrm{L}}^{2}=\mathrm{E}\left[\mathrm{E}\left(\mathrm{D}\left([-\mathrm{L}, \mathrm{L}]^{\mathrm{d}} \cap \mathrm{P}, \mathrm{Q}(0) ; \alpha\right) \mid \mathrm{F}\right)\right. \\
\left.\quad-\mathrm{E}\left(\mathrm{D}\left([-\mathrm{L}, \mathrm{L}]^{\mathrm{d}} \cap \mathrm{P}, \mathrm{Q}(0) ; \alpha\right) \mid \mathrm{F}^{\prime}\right)\right]^{2} \\
=\mathrm{E}\left[\mathrm{E}\left(\tilde{\mathrm{D}}_{\mathrm{L}}(0 ; \mathrm{P}, \alpha) \mid \mathrm{F}\right)-\mathrm{E}\left(\tilde{\mathrm{D}}_{\mathrm{L}}(0 ; \mathrm{P}, \alpha) \mid \mathrm{F}^{\prime}\right)\right]^{2},
\end{aligned}
$$

and where

$$
\begin{gathered}
\mathrm{F}=\sigma\left(\mathrm{Q}(\mathrm{x}) \cap \mathrm{P}: \mathrm{x} \in \mathrm{Z}^{\mathrm{d}}, \mathrm{Q}(\mathrm{x}) \cap[-\mathrm{L}, \mathrm{L}]^{\mathrm{d}} \neq \varnothing, \mathrm{x}\right. \text { strictly } \\
\text { precedes } 0 \text { in the lexicographical order or } \mathrm{x}=0), \\
\mathrm{F}^{\prime}=\sigma\left(\mathrm{Q}(\mathrm{x}) \cap \mathrm{P}: \mathrm{x} \in \mathrm{Z}^{\mathrm{d}}, \mathrm{Q}(\mathrm{x}) \cap[-\mathrm{L}, \mathrm{L}]^{\mathrm{d}} \neq \varnothing, \mathrm{x}\right. \text { strictly } \\
\text { precedes } 0 \text { in the lexicographical order }) ; \\
\text { 14) } \lim _{\mathrm{L} \rightarrow \infty} \tau_{\mathrm{L}}^{2} \text { exists and } 0<\tau^{2}:=\lim _{\mathrm{L} \rightarrow \infty} \tau_{\mathrm{L}}^{2}<\infty ;
\end{gathered}
$$

for all $\varepsilon>0$, there exists an $L=L(\varepsilon)$ and, for each $L^{\prime} \geq L$, an $n_{1}=n_{1}\left(L^{\prime}\right)$ such that for $L^{\prime} \geq L, n \geq n_{1}$,

$$
\frac{1}{\mathrm{n}} \sum_{\mathrm{k}} \mathrm{E}\left|\Delta_{\mathrm{k}}^{2}-\Delta_{\mathrm{k}, \mathrm{L}^{\prime}}^{2}\right| \leq \varepsilon .
$$

Relation (3.13) follows from a weak law of large numbers: we merely note that $\Delta_{\mathrm{k}, \mathrm{L}}^{2}$ and $\Delta_{\mathrm{K}^{\prime}, \mathrm{L}}^{2}$ are independent as long as

$$
\prod\left[(\mathrm{v}(\mathrm{k}))_{\mathrm{i}}-\mathrm{L},(\mathrm{v}(\mathrm{k}))_{\mathrm{i}}+\mathrm{L}\right] \cap \prod\left[\left(\mathrm{v}\left(\mathrm{k}^{\prime}\right)\right)_{\mathrm{i}}-\mathrm{L},\left(\mathrm{v}\left(\mathrm{k}^{\prime}\right)\right)_{\mathrm{i}}+\mathrm{L}\right]=\varnothing
$$

and that they are identically distributed with mean $\tau_{\mathrm{L}}^{2}$ as long as $\mathrm{v}(\mathrm{k})$ and $\mathrm{v}\left(\mathrm{k}^{\prime}\right)$ are away from the boundary of $\mathrm{Q}_{\mathrm{n}}$. The contribution of the $\Delta_{\mathrm{k}, \mathrm{L}}^{2} \mathrm{~S}, \mathrm{v}(\mathrm{k})$ close to $\partial \mathbf{Q}_{n}$, to the sum in (3.13) is negligible by (3.12).

Relation (3.14) follows from Proposition 1: by Proposition 1, as $L \rightarrow \infty$,

$$
\tilde{\mathrm{D}}_{\mathrm{L}}(0 ; \mathrm{P}, \alpha) \rightarrow \tilde{\mathrm{D}}_{\mathrm{L}_{1}}(0 ; \mathrm{P}, \alpha) \text { a.s. }
$$


By Chebyshev's inequality we have

$$
\begin{aligned}
\mathrm{P}(\mid \mathrm{E} & \left.\left(\tilde{\mathrm{D}}_{\mathrm{L}}(0 ; \mathrm{P}, \alpha) \mid \mathrm{F}\right)-\mathrm{E}\left(\tilde{\mathrm{D}}_{\mathrm{L}_{1}}(0 ; \mathrm{P}, \alpha) \mid \mathrm{F}\right) \mid \geq \varepsilon\right) \\
& \leq \mathrm{P}\left(\mathrm{E}\left(\left|\tilde{\mathrm{D}}_{\mathrm{L}}(0 ; \mathrm{P}, \alpha)-\tilde{\mathrm{D}}_{\mathrm{L}_{1}}(0 ; \mathrm{P}, \alpha)\right| \mid \mathrm{F}\right) \geq \varepsilon\right) \\
& \leq \frac{1}{\varepsilon} \mathrm{E}\left|\tilde{\mathrm{D}}_{\mathrm{L}}(0 ; \mathrm{P}, \alpha)-\tilde{\mathrm{D}}_{\mathrm{L}_{1}}(0 ; \mathrm{P}, \alpha)\right| .
\end{aligned}
$$

Since, by Lemma 11, $\left\{\tilde{D}_{\mathrm{L}}(0 ; \mathrm{P}, \alpha), \tilde{\mathrm{D}}_{\mathrm{L}_{1}}(0 ; \mathrm{P}, \alpha)\right.$ : $\left.\mathrm{L}>0\right\}$ are uniformly integrable, by (3.16) as $\mathrm{L} \rightarrow \infty$ we have $\mathrm{E}\left|\tilde{D}_{\mathrm{L}}(0 ; \mathrm{P}, \alpha)-\tilde{\mathrm{D}}_{\mathrm{L}_{1}}(0 ; \mathrm{P}, \alpha)\right| \rightarrow 0$ and $\mathrm{E}\left(\tilde{\mathrm{D}}_{\mathrm{L}}(0 ; \mathrm{P}, \alpha) \mid \mathrm{F}\right) \rightarrow \mathrm{E}\left(\tilde{\mathrm{D}}_{\mathrm{L}_{1}}(0 ; \mathrm{P}, \alpha) \mid \mathrm{F}\right)$ in probability. Similarly, as $\mathrm{L} \rightarrow \infty$ we have $\mathrm{E}\left(\tilde{\mathrm{D}}_{\mathrm{L}}(0 ; \mathrm{P}, \alpha) \mid \mathrm{F}^{\prime}\right) \rightarrow \mathrm{E}\left(\tilde{\mathrm{D}}_{\mathrm{L}_{1}}(0 ; \mathrm{P}, \alpha) \mid \mathrm{F}^{\prime}\right)$ in probability, and hence

$$
\begin{aligned}
& {\left[\mathrm{E}\left(\tilde{\mathrm{D}}_{\mathrm{L}}(0 ; \mathrm{P}, \alpha) \mid \mathrm{F}\right)-\mathrm{E}\left(\tilde{\mathrm{D}}_{\mathrm{L}}(0 ; \mathrm{P}, \alpha) \mid \mathrm{F}^{\prime}\right)\right]^{2}} \\
& \quad \rightarrow\left[\mathrm{E}\left(\tilde{\mathrm{D}}_{\mathrm{L}_{1}}(0 ; \mathrm{P}, \alpha) \mid \mathrm{F}\right)-\mathrm{E}\left(\tilde{\mathrm{D}}_{\mathrm{L}_{1}}(0 ; \mathrm{P}, \alpha) \mid \mathrm{F}^{\prime}\right)\right]^{2}
\end{aligned}
$$

in probability. Since, again by Lemma 11 ,

$$
\begin{aligned}
& \left\{\left[E\left(\tilde{D}_{\mathrm{L}}(0 ; \mathrm{P}, \alpha) \mid \mathrm{F}\right)-\mathrm{E}\left(\tilde{\mathrm{D}}_{\mathrm{L}}(0 ; \mathrm{P}, \alpha) \mid \mathrm{F}^{\prime}\right)\right]^{2},\right. \\
& \left.\quad\left[\mathrm{E}\left(\tilde{\mathrm{D}}_{\mathrm{L}_{1}}(0 ; \mathrm{P}, \alpha) \mid \mathrm{F}\right)-\mathrm{E}\left(\tilde{\mathrm{D}}_{\mathrm{L}_{1}}(0 ; \mathrm{P}, \alpha) \mid \mathrm{F}^{\prime}\right)\right]^{2}: \mathrm{L}>0\right\}
\end{aligned}
$$

are uniformly integrable, by (3.17) as $\mathrm{L} \rightarrow \infty$,

$$
\begin{aligned}
& \mathrm{E}\left[\mathrm{E}\left(\tilde{\mathrm{D}}_{\mathrm{L}}(0 ; \mathrm{P}, \alpha) \mid \mathrm{F}\right)-\mathrm{E}\left(\tilde{\mathrm{D}}_{\mathrm{L}}(0 ; \mathrm{P}, \alpha) \mid \mathrm{F}^{\prime}\right)\right]^{2} \\
& \quad \rightarrow \mathrm{E}\left[\mathrm{E}\left(\tilde{\mathrm{D}}_{\mathrm{L}_{1}}(0 ; \mathrm{P}, \alpha) \mid \mathrm{F}\right)-\mathrm{E}\left(\tilde{\mathrm{D}}_{\mathrm{L}_{1}}(0 ; \mathrm{P}, \alpha) \mid \mathrm{F}^{\prime}\right)\right]^{2}
\end{aligned}
$$

and

$$
\tau^{2}:=\mathrm{E}\left[\mathrm{E}\left(\tilde{\mathrm{D}}_{\mathrm{L}_{1}}(0 ; \mathrm{P}, \alpha) \mid \mathrm{F}\right)-\mathrm{E}\left(\tilde{\mathrm{D}}_{\mathrm{L}_{1}}(0 ; \mathrm{P}, \alpha) \mid \mathrm{F}^{\prime}\right)\right]^{2}<\infty .
$$

Therefore, as $L \rightarrow \infty, \tau_{L}^{2}$ converges to $\tau^{2}$ and $\tau^{2}<\infty$. To prove $\tau^{2}>0$, one can use a block argument which is similar to that of Kesten and Lee [(1996), Theorem 2, pages 525-527]. Here, we just describe our block for $d=2$ and $\alpha=1$. For $d=2$ and $\alpha=1$, we consider the block $[-200,200]^{2}$. For each lattice point $\left(n_{1}, n_{2}\right)$ on $\left(\partial[-100,100]^{2}\right) \cup([-100,0] \times\{0\})$, we require that there exists exactly one $P$-point very near $\left(n_{1}, n_{2}\right)$. Denote the $P$-point near $(0,0)$ by $v_{0}$. We also require that there exists exactly one $P$-point $v_{+}$very near $(\sqrt{3} / 2,1 / 2)$ and that there exists exactly one $P$-point $v_{-}$very near $(\sqrt{3} / 2,-1 / 2)$. Finally, we require that except these $902 \mathrm{P}$-points there are no other $P$-points on the block $[-200,200]^{2}$. The main feature of this block is that the minimal spanning tree structure around the origin is locally determined. If a finite subset $A$ of $P$ contains these 902 points, then the edges, in the MST T (A) on A, from $v_{0}, v_{+}, v_{-}$are completely determined by these 902 points. Moreover, the degrees of $\mathrm{v}_{+}$and $\mathrm{v}_{-}$in $\mathrm{T}(\mathrm{A})$ are completely determined by the relative position of the three points $v_{0}, v_{+}, v_{-}$. The possible 
values for the degrees of $v_{+}$and $v_{-}$are 1 and 2 , and these two possible values can be actually realized according to the relative position of $\mathrm{v}_{0}, \mathrm{v}_{+}, \mathrm{v}_{-}$.

Relation (3.15) follows again from Proposition 1: by Proposition 1 and Lemma 11, as $L^{\prime} \rightarrow \infty,\left|\Delta_{k}^{2}-\Delta_{k, L^{\prime}}^{2}\right| \rightarrow 0$ in probability (uniformly in $n$ and $k$ with $\left.v(k) \in\left[-n^{1 / d} / 2+L^{\prime}, n^{1 / d} / 2-L^{\prime}\right]^{d}\right)$. Moreover, by Lemma 11 they are uniformly $\left[\right.$ in $\left.\left(L^{\prime}, n, k\right)\right]$ integrable. Therefore, (3.15) holds [the contribution of the $E \mid \Delta_{k}^{2}-\Delta_{k, L^{\prime}}^{2}{ }^{\prime} S, v(k)$ close to $\partial Q_{n}$, to the sum in (3.15) is negligible by (3.12)].

4. De-Poissonization. In this section, we de-Poissonize Theorem 1 and prove Theorem 2. Again, it is more natural for the proof to rescale the point process so that the density of the point set remains constant. So, actually we prove in this section that, for each strictly positive integer $\alpha$ such that $\mathrm{P}\left(\mathrm{N}\left(\mathrm{P}_{1}(1) ; \alpha\right)=1\right)>0$, as $\mathrm{n} \rightarrow \infty$,

$$
\frac{\mathrm{N}\left(\mathrm{U}_{\mathrm{n}} ; \alpha\right)-\mathrm{EN}\left(\mathrm{U}_{\mathrm{n}} ; \alpha\right)}{\mathrm{n}^{1 / 2}} \rightarrow \mathrm{N}\left(0, \sigma^{2}(\alpha, \mathrm{d})\right)
$$

in distribution for some $0<\sigma^{2}(\alpha, d)<\infty$, where $U_{n}(m)$ is the set of $m$ i.i.d. uniform points on $Q_{n}$ and where $U_{n}=U_{n}(n)$.

LemMA 12. Define, for each $\alpha$,

Then,

$$
\rho_{\mathrm{L}}(\alpha)=\mathrm{E}\left(\mathrm{D}_{\mathrm{L}}(0 ; \mathrm{P} \cup\{0\}, \alpha)\right) .
$$

$$
\lim _{\mathrm{L} \rightarrow \infty} \rho_{\mathrm{L}}(\alpha) \text { exists and } \rho(\alpha):=\lim _{\mathrm{L} \rightarrow \infty} \rho_{\mathrm{L}}(\alpha) \text { is finite. }
$$

Moreover, for $A>0, \varepsilon>0$, there exists an $\mathrm{n}_{2}=\mathrm{n}_{2}(A, \varepsilon)$ such that, for $\mathrm{n} \geq \mathrm{n}_{2}, \alpha, \mathrm{n}-\mathrm{An}^{1 / 2} \leq \mathrm{S} \leq \mathrm{n}+\mathrm{An}^{1 / 2}$,

$$
\mathrm{P}\left(\left|\mathrm{N}\left(\mathrm{U}_{\mathrm{n}}(\mathrm{s}) ; \alpha\right)-\mathrm{N}\left(\mathrm{U}_{\mathrm{n}} ; \alpha\right)-(\mathrm{s}-\mathrm{n}) \rho(\alpha)\right| \geq \varepsilon \mathrm{n}^{1 / 2}\right) \leq \varepsilon .
$$

Proof. By Proposition 1 , as $\mathrm{L} \rightarrow \infty, \mathrm{D}_{\mathrm{L}}(0 ; \mathrm{P} \cup\{0\}, \alpha)$ converges with probability 1. Moreover, by Lemma 11 they are uniformly integrable. So (4.2) holds.

For $\mathrm{n}-\mathrm{An} \mathrm{n}^{1 / 2} \leq \mathrm{S} \leq \mathrm{n}+\mathrm{An} \mathrm{n}^{1 / 2}$,

$$
\begin{aligned}
& \left|\mathrm{N}\left(\mathrm{U}_{\mathrm{n}}(\mathrm{s}) ; \alpha\right)-\mathrm{N}\left(\mathrm{U}_{\mathrm{n}} ; \alpha\right)-(\mathrm{s}-\mathrm{n}) \rho(\alpha)\right| \\
& =\left|\sum_{\mathrm{p}=(\mathrm{s} \wedge \mathrm{n})+1}^{(\mathrm{s} \vee \mathrm{n})}\left[\mathrm{D}\left(\mathrm{U}_{\mathrm{n}}(\mathrm{p}),\left\{\mathrm{X}_{\mathrm{p}}^{(\mathrm{n})}\right\} ; \alpha\right)-\rho(\alpha)\right]\right| \\
& \leq \sum_{\mathrm{p}=\mathrm{n}-\mathrm{An}^{1 / 2}}^{\mathrm{n}+\mathrm{An}^{1 / 2}}\left|\Omega_{\mathrm{L}}\left(\mathrm{X}_{\mathrm{p}}^{(\mathrm{n})} ; \alpha\right)\right|+\left|\sum_{\mathrm{p}=(\mathrm{s} \wedge \mathrm{n})+1}^{(\mathrm{s} \vee \mathrm{n})} \mathrm{Z}_{\mathrm{L}}\left(\mathrm{X}_{\mathrm{p}}^{(\mathrm{n})} ; \alpha\right)\right| \\
& \quad+\sum_{\mathrm{p}=\mathrm{n}-\mathrm{An}^{1 / 2}}^{\mathrm{n}+\mathrm{An}^{1 / 2}}\left|\mathrm{E}\left(\mathrm{D}_{\mathrm{L}}\left(\mathrm{X}_{\mathrm{p}}^{(\mathrm{n})} ; \mathrm{U}_{\mathrm{n}}(\mathrm{p}), \alpha\right)\right)-\rho_{\mathrm{L}}(\alpha)\right| \\
& \quad+\left(1+2 \mathrm{An}^{1 / 2}\right)\left|\rho_{\mathrm{L}}(\alpha)-\rho(\alpha)\right|,
\end{aligned}
$$


where

$$
\Omega_{\mathrm{L}}\left(\mathrm{X}_{\mathrm{p}}^{(\mathrm{n})} ; \alpha\right)=\mathrm{D}\left(\mathrm{U}_{\mathrm{n}}(\mathrm{p}),\left\{\mathrm{X}_{\mathrm{p}}^{(\mathrm{n})}\right\} ; \alpha\right)-\mathrm{D}_{\mathrm{L}}\left(\mathrm{X}_{\mathrm{p}}^{(\mathrm{n})} ; \mathrm{U}_{\mathrm{n}}(\mathrm{p}), \alpha\right)
$$

and

$$
\mathrm{Z}_{\mathrm{L}}\left(\mathrm{X}_{\mathrm{p}}^{(\mathrm{n})} ; \alpha\right)=\mathrm{D}_{\mathrm{L}}\left(\mathrm{X}_{\mathrm{p}}^{(\mathrm{n})} ; \mathrm{U}_{\mathrm{n}}(\mathrm{p}), \alpha\right)-\mathrm{ED}_{\mathrm{L}}\left(\mathrm{X}_{\mathrm{p}}^{(\mathrm{n})} ; \mathrm{U}_{\mathrm{n}}(\mathrm{p}), \alpha\right) .
$$

Choose an $L$, by (4.2), such that

$$
\left|\rho_{\mathrm{L}}(\alpha)-\rho(\alpha)\right| \leq \frac{\varepsilon}{8(\mathrm{~A}+1)} .
$$

So, the last term in (4.4) satisfies

$$
\left(1+2 \mathrm{An}^{1 / 2}\right)\left|\rho_{\mathrm{L}}(\alpha)-\rho(\alpha)\right| \leq \frac{1}{4} \varepsilon \mathrm{n}^{1 / 2} .
$$

Since, as $\mathrm{n} \rightarrow \infty$, the distribution of the translation (with the restriction to $\left.[-L, L]^{d}\right)\left(U_{n}(p-1)-X_{p}^{(n)}\right) \cap[-L, L]^{d}$ of $U_{n}(p-1)$-points by $X_{p}^{(n)}$ converges to that of a Poisson field with mean 1 on $[-L, L]^{d}$ and since, by Lemma 11 , as $\mathrm{n} \rightarrow \infty, \mathrm{E}\left(\mathrm{D}_{\mathrm{L}}\left(\mathrm{X}_{\mathrm{p}}^{(\mathrm{n})} ; \mathrm{U}_{\mathrm{n}}(\mathrm{p}), \alpha\right)\right)$ converges to $\rho_{\mathrm{L}}(\alpha)=\mathrm{E}\left(\mathrm{D}_{\mathrm{L}}(0\right.$; $\mathrm{P} \cup\{0\}, \alpha)$ ) uniformly in $\mathrm{n}-\mathrm{An} \mathrm{n}^{1 / 2} \leq \mathrm{p} \leq \mathrm{n}+\mathrm{A} \mathrm{n}^{1 / 2}$, we can choose an $\mathrm{n}_{1}$ such that, for $n \geq n_{1}, n-A n^{1 / 2} \leq p \leq n+A n^{1 / 2}$,

$$
\left|\mathrm{E}\left(\mathrm{D}_{\mathrm{L}}\left(\mathrm{X}_{\mathrm{p}}^{(\mathrm{n})} ; \mathrm{U}_{\mathrm{n}}(\mathrm{p}), \alpha\right)\right)-\rho_{\mathrm{L}}(\alpha)\right| \leq \frac{\varepsilon}{8(\mathrm{~A}+1)} .
$$

Since $U_{n}(p)$ is $P_{n}$ in distribution if $\left|P_{n}\right|=p$, by Proposition 1 we can actually choose an $n_{1}$ and an $L$ (by enlarging $n_{1}$ and $L$ if necessary) such that, for $\mathrm{n} \geq \mathrm{n}_{1}, \mathrm{n}-\mathrm{An^{1/2 }} \leq \mathrm{p} \leq \mathrm{n}+\mathrm{An} \mathrm{n}^{1 / 2}$,

$$
\mathrm{P}\left(\Omega_{\mathrm{L}}\left(\mathrm{X}_{\mathrm{p}}^{(\mathrm{n})} ; \alpha\right) \neq 0\right) \leq \frac{\varepsilon^{2}}{32\left(\mathrm{D}_{\mathrm{d}}+1\right)(\mathrm{A}+1)} .
$$

Construct $U_{n}\left(n+A n^{1 / 2}\right)$ from $P$ in the following way. First, we choose the smallest $N(n, A)$ such that

$$
\left|P_{N(n, A)}\right|=n+A n^{1 / 2} \text {. }
$$

Second, we choose a random scaling factor $S(n, A)$ so that the distribution of $S(n, A) P_{N(n, A)}$ is the same as that of $U_{n}\left(n+A n^{1 / 2}\right)$.

Finally, we give the names $X_{1}^{(n)}, X_{2}^{(n)}, \ldots, X_{n+A n^{1 / 2}}^{(n)}$ to the points $S(n$, A) $P_{N(n, A)}$ randomly. If, for $B=B[x, y] \supset\left(S(n, A)^{-1} X_{p}^{(n)}+[-L / 2, L / 2]^{d}\right)$,

$$
\begin{gathered}
D\left((P \cap B) \cup\left\{S(n, A)^{-1} X_{p}^{(n)}\right\},\left\{S(n, A)^{-1} X_{p}^{(n)}\right\} ; \alpha\right) \\
=D_{L / 2}\left(S(n, A)^{-1} X_{p}^{(n)} ; P, \alpha\right), \\
|S(n, A)-1| \leq \frac{1}{2}, \\
X_{p}^{(n)} \notin\left(\left[-n^{1 / d} / 2, n^{1 / d} / 2\right]^{d} \backslash\left[-n^{1 / d} / 2+L, n^{1 / d} / 2-L\right]^{d}\right),
\end{gathered}
$$


then by the construction of $U_{n}\left(n+A n^{1 / 2}\right)$ we have $\Omega_{L}\left(X_{p}^{(n)} ; \alpha\right)=0$. So

$$
\begin{aligned}
& \mathrm{P}\left(\Omega_{\mathrm{L}}\left(\mathrm{X}_{\mathrm{p}}^{(\mathrm{n})} ; \alpha\right) \neq 0\right) \\
& \leq \mathrm{P}\left(\mathrm{L}_{2} \geq \mathrm{L} / 2\right)+\mathrm{P}\left(|\mathrm{S}(\mathrm{n}, \mathrm{A})-1| \geq \frac{1}{2}\right) \\
& \quad+\mathrm{P}\left(\mathrm { X } _ { \mathrm { p } } ^ { ( \mathrm { n } ) } \in \left(\left[-\mathrm{n}^{1 / d} / 2, \mathrm{n}^{1 / d} / 2\right]^{d} \backslash\right.\right. \\
& \left.\left.\quad\left[-\mathrm{n}^{1 / d} / 2+\mathrm{L}, \mathrm{n}^{1 / d} / 2-L\right]^{d}\right)\right) .
\end{aligned}
$$

By Proposition 1 we can choose $L$ (by enlarging $L$ if necessary) such that

$$
P\left(L_{2} \geq L / 2\right) \leq \frac{\varepsilon^{2}}{96\left(D_{d}+1\right)(A+1)} .
$$

Also, by the construction of $U_{n}\left(n+A n^{1 / 2}\right)$ we can choose an $n_{1}$ (by enlarging $n_{1}$ if necessary) such that, for $n \geq n_{1}, n-A n^{1 / 2} \leq p \leq n+A n^{1 / 2}$,

$$
P(|S(n, A)-1| \geq 1 / 2) \leq \frac{\varepsilon^{2}}{96\left(D_{d}+1\right)(A+1)},
$$

and

$$
\begin{aligned}
& P\left(X_{p}^{(n)} \in\left(\left[-n^{1 / d} / 2, n^{1 / d} / 2\right]^{d} \backslash\left[-n^{1 / d} / 2+L, n^{1 / d} / 2-L\right]^{d}\right)\right) \\
& \quad \leq \frac{\varepsilon^{2}}{96\left(D_{d}+1\right)(A+1)} .
\end{aligned}
$$

Therefore, (4.10) indeed follows from (4.11)-(4.14).

By (4.9), the third term in (4.4) satisfies, for $n \geq n_{1}$,

$$
\sum_{\mathrm{n}-\mathrm{An}^{1 / 2}}^{\mathrm{n}+\mathrm{An}^{1 / 2}}\left|\mathrm{E}\left(\mathrm{D}_{\mathrm{L}}\left(\mathrm{X}_{\mathrm{p}}^{(\mathrm{n})} ; \mathrm{U}_{\mathrm{n}}(\mathrm{p}), \alpha\right)\right)-\rho_{\mathrm{L}}(\alpha)\right| \leq \frac{1}{4} \varepsilon \mathrm{n}^{1 / 2} .
$$

By (4.10), the first term in (4.4) satisfies

$$
\begin{aligned}
& \mathrm{P}\left(\sum_{\mathrm{n}-\mathrm{An} \mathrm{n}^{1 / 2}}^{\mathrm{n}+\mathrm{An} \mathrm{n}^{1 / 2}}\left|\Omega_{\mathrm{L}}\left(\mathrm{X}_{\mathrm{p}}^{(\mathrm{n})} ; \alpha\right)\right| \geq \frac{1}{4} \varepsilon \mathrm{n}^{1 / 2}\right) \\
& \quad \leq\left(\sum_{\mathrm{n}-\mathrm{An}^{1 / 2}}^{\mathrm{n}+\mathrm{An^{1/2 }}} \mathrm{E}\left|\Omega_{\mathrm{L}}\left(\mathrm{X}_{\mathrm{p}}^{(\mathrm{n})} ; \alpha\right)\right|\right) /\left(\frac{1}{4} \varepsilon \mathrm{n}^{1 / 2}\right) \\
& \quad \leq\left(\sum_{\mathrm{n}-\mathrm{An}^{1 / 2}}^{\mathrm{n}+\mathrm{An}^{1 / 2}} 2\left(\mathrm{D}_{\mathrm{d}}+1\right) \mathrm{P}\left(\Omega_{\mathrm{L}}\left(\mathrm{X}_{\mathrm{p}}^{(\mathrm{n})} ; \alpha\right) \neq 0\right)\right) /\left(\frac{1}{4} \varepsilon \mathrm{n}^{1 / 2}\right) \\
& \quad \leq \varepsilon / 2 .
\end{aligned}
$$

The first inequality follows from the argument for (3.12) and the second holds by (4.10). 
Now, we handle the second term in (4.4). By the argument for (3.12),

$$
\left|Z_{L}\left(X_{p}^{(n)} ; \alpha\right)\right| \leq 2\left(D_{d}+1\right) \text {, }
$$

and, by (4.6),

$$
\mathrm{E}\left(\mathrm{Z}_{\mathrm{L}}\left(\mathrm{X}_{\mathrm{p}}^{(\mathrm{n})} ; \alpha\right)\right)=0 \text {. }
$$

The $\mathrm{Z}_{\mathrm{L}}\left(\mathrm{X}_{\mathrm{p}}^{(\mathrm{n})} ; \alpha\right)$ 's are not independent, but as $\mathrm{n} \rightarrow \infty$ the joint distribution of $\left(U_{n}\left(p_{1}-1\right)-X_{p_{1}}^{(n)}\right) \cap[-L, L]^{d}$ and $\left(U_{n}\left(p_{2}-1\right)-X_{p_{2}}^{(n)}\right) \cap[-L, L]^{d}$ converges to the distribution of two independent Poisson fields on $[-L, L]^{d}$ for $n-A n^{1 / 2} \leq p_{1} \neq p_{2} \leq n+A n^{1 / 2}$. So, by (4.17) and (4.18),

$$
\mathrm{EZ}_{\mathrm{L}}\left(\mathrm{X}_{\mathrm{p}_{1}}^{(\mathrm{n})} ; \alpha\right) \mathrm{Z}_{\mathrm{L}}\left(\mathrm{X}_{\mathrm{p}_{2}}^{(\mathrm{n})} ; \alpha\right) \rightarrow 0
$$

uniformly in $n-A n^{1 / 2} \leq p_{1} \neq p_{2} \leq n+A n^{1 / 2}$. Hence,

$$
\frac{1}{n} E\left(\sum_{p_{1}}^{p_{2}} Z_{L}\left(X_{p}^{(n)} ; \alpha\right)\right)^{2} \rightarrow 0,
$$

uniformly in $\mathrm{n}-\mathrm{A} \mathrm{n}^{1 / 2} \leq \mathrm{p}_{1} \leq \mathrm{p}_{2} \leq \mathrm{n}+\mathrm{A} \mathrm{n}^{1 / 2}$. Therefore, we can choose an $\mathrm{n}_{2} \geq \mathrm{n}_{1}$ such that, for $\mathrm{n} \geq \mathrm{n}_{2}, \mathrm{n}-A \mathrm{n}^{1 / 2} \leq \mathrm{S} \leq \mathrm{n}+A \mathrm{n}^{1 / 2}$,

$$
\mathrm{P}\left(\left|\sum_{\mathrm{p}=(\mathrm{s} \wedge \mathrm{n})+1}^{(\mathrm{s} \vee \mathrm{n})} \mathrm{Z}_{\mathrm{L}}\left(\mathrm{X}_{\mathrm{p}}^{(\mathrm{n})} ; \alpha\right)\right| \geq \frac{1}{4} \varepsilon \mathrm{n}^{1 / 2}\right) \leq \frac{\varepsilon}{2} .
$$

Now, (4.3) follows from (4.16), (4.19), (4.15) and (4.8).

Couple $P_{n}$ and $U_{n}(m)$ in the following way. Choose an infinite sequence $\left\{X_{i}^{(n)}: i \geq 1\right\}$ of i.i.d. uniform random variables on $Q_{n}$ and a Poisson variable $N_{n}$ with mean $n$, independently of $\left\{X_{i}^{(n)}\right\}$. Then, $\left\{X_{1}^{(n)}, \ldots, X_{N_{n}}^{(n)}\right\}$ forms a realization of $P_{n}$ and $\left\{X_{1}^{(n)}, \ldots, X_{m}^{(n)}\right\}$ forms a realization of $U_{n}(m)$. In particular, by Lemma 12 , as $\mathrm{n} \rightarrow \infty$,

$$
\frac{\mathrm{N}\left(\mathrm{P}_{\mathrm{n}} ; \alpha\right)-\mathrm{N}\left(\mathrm{U}_{\mathrm{n}} ; \alpha\right)-\left(\mathrm{N}_{\mathrm{n}}-\mathrm{n}\right) \rho(\alpha)}{\mathrm{n}^{1 / 2}} \rightarrow 0 \text { in probability. }
$$

By Theorem 1, as $\mathrm{n} \rightarrow \infty$,

$$
\frac{\mathrm{N}\left(\mathrm{P}_{\mathrm{n}} ; \alpha\right)-\mathrm{EN}\left(\mathrm{P}_{\mathrm{n}} ; \alpha\right)}{\mathrm{n}^{1 / 2}} \rightarrow \mathrm{N}\left(0, \tilde{\sigma}^{2}(\alpha, \mathrm{d})\right) \text { in distribution. }
$$

Thus, by (4.20) and (4.21), as $n \rightarrow \infty$,

$$
\frac{\mathrm{N}\left(\mathrm{U}_{\mathrm{n}} ; \alpha\right)-\mathrm{EN}\left(\mathrm{P}_{\mathrm{n}} ; \alpha\right)+\left(\mathrm{N}_{\mathrm{n}}-\mathrm{n}\right) \rho(\alpha)}{\mathrm{n}^{1 / 2}}
$$


Since $N_{n}$ is independent of $U_{n}$ and since, as $n \rightarrow \infty,\left(N_{n}-n\right) / n^{1 / 2} \rightarrow N(0,1)$ in distribution, by (4.22), as $n<\infty$,

$$
\begin{aligned}
& \frac{\mathrm{N}\left(\mathrm{U}_{\mathrm{n}} ; \alpha\right)-\mathrm{EN}\left(\mathrm{P}_{\mathrm{n}} ; \alpha\right)}{\mathrm{n}^{1 / 2}} \\
& \quad \rightarrow \mathrm{N}\left(0, \tilde{\sigma}^{2}(\alpha, \mathrm{d})-\rho(\alpha)^{2}\right) \text { in distribution. }
\end{aligned}
$$

To replace $\mathrm{EN}\left(\mathrm{P}_{n} ; \alpha\right)$ by $\mathrm{EN}\left(\mathrm{U}_{n} ; \alpha\right)$ in (4.23), we observe that the random variables on the left-hand side of (4.20) are uniformly integrable, because, by the argument for (3.12),

$$
\left|\mathrm{N}\left(\mathrm{P}_{\mathrm{n}} ; \alpha\right)-\mathrm{N}\left(\mathrm{U}_{\mathrm{n}} ; \alpha\right)\right| \leq\left(\mathrm{D}_{\mathrm{d}}+1\right)\left|\mathrm{N}_{\mathrm{n}}-\mathrm{n}\right| .
$$

So, as $\mathrm{n} \rightarrow \infty$,

$$
\frac{\mathrm{EN}\left(\mathrm{P}_{\mathrm{n}} ; \alpha\right)-\mathrm{EN}(\mathrm{U} \mathrm{n} ; \alpha)}{\mathrm{n}^{1 / 2}} \rightarrow 0 .
$$

Therefore, Theorem 2 holds with $\sigma^{2}(\alpha, \mathrm{d})=\tilde{\sigma}^{2}(\alpha, \mathrm{d})-\rho(\alpha)^{2}$. The argument for $\sigma^{2}(\alpha, \mathrm{d})>0$ is the same as that for $\tilde{\sigma}^{2}(\alpha, \mathrm{d})>0$ in Section 3 .

Acknowledgments. The author would like to thank Michael Steele for drawing the problem to author's attention, and Harry Kesten and the referee for their thoughtful comments on an earlier version.

\section{REFERENCES}

Aldous, D. and Steele, J. M. (1992). Asymptotics for Euclidean minimal spanning trees on random points. Probab. Theory Related Fields 92 247-258.

Alexander, K. S. (1995). Simultaneous uniqueness of infinite clusters in stationary random labeled graphs. Comm. Math. Phys. 168 39-55.

Alexander, K. S. (1996). The RSW theorem for continuum percolation and the CLT for Euclidean minimal spanning trees. Ann. Appl. Probab. 6 466-494.

BentLey, J. L. and Friedman, J. H. (1978). Fast algorithms for constructing minimal spanning trees in coordinate spaces. IEEE Comput. 27 97-105.

Chang, C. L., Chang, S. K., Kang, A. N. C. and LeE, R. C. T. (1977). Storage reduction through minimal spanning trees and spanning forests. IEEE Comput. 26 425-434.

CHIN, F. Y. and HouCK, D. J . (1978). Algorithms for updating minimal spanning trees. J . Comput. System Sci. 16 333-344.

Dussert, C., Llebaria, A., Marty, F., Palmari, J ., Rasigni, G. and Rasigni, M. (1987). Minimal spanning tree analysis of biological structures. J. Theoret. Biol. 125 317-323.

Eddy, W. F., Shepp, L. A. and Steele, J. M. (1987). On the number of leaves of a Euclidean minimal spanning tree. J. Appl. Probab. 24 809-826.

Friedman, J. H. and RAFSKY, L. C. (1979). Multivariate generalizations of the Wolfowitz and Smirnov two-sample tests. Ann. Statist. 7 697-717.

FrIEDMAN, J . H. and RAFSKY, L. C. (1983). Graph-theoretic measures of multivariate association and prediction. Ann. Statist. 11 377-391.

HALL, P. and HEYDE, C. C. (1980). Martingale Limit Theory and Its Application. Academic Press, New York.

J UNG, H. A. (1974). Determination of minimal paths and spanning trees in graphs. Computing 13249.

KATAJ AINEN, J . (1983). On the worst case of a minimal spanning tree algorithm for Euclidean space. BIT 23 2-8. 
Kesten, H. and LEE, S. (1996). The central limit theorem for weighted minimal spanning trees on random point. Ann. Appl. Probab. 6 495-527.

KRUSKAL, J . B. (1956). On the shortest spanning subtree of a graph and the traveling salesman problem. Proc. Amer. Math. Soc. 7 48-50.

LÉVY, P. (1937). Théorie de I'Addition des Variables Aléatoires. Gauthier-Villars, Paris.

MALLION, R. B. (1975). Number of spanning trees in a molecular graph. Chem. Phys. Lett. 36 170-174.

MCLEISH, D. L. (1974). Dependent central limit theorems and invariance principles. Ann. Probab. 2 620-628.

PenNy, D. (1980). Techniques for the verification of minimal phylogenetic trees illustrated with 10 mammalian hemogl obin sequences. Biochem. J . 187 65-74.

Penrose, M. D. (1996). The random minimal spanning tree in high dimensions. Ann. Probab. 6 528-544

REDMOND, C. and YUKICH, J . E. (1994). Limit theorems and rates of convergence for Euclidean functionals. Ann. Appl. Probab. 4 1057-1073.

RheE, W. T. and TALAGRAND, M. (1989). A sharp deviation inequality for the stochastic traveling salesman problem. Ann. Probab. 17 1-8.

RoHLF, F. J. (1975). Generalization of the gap test for the detection of multivariate outliers. Biometrics 31 93-101.

Romane, F. (1977). Possible use of minimum spanning tree in phytoecology. Vegetation 33 99-106.

Rosen, K. H. (1995). Discrete Mathematics and Its Applications, 3rd ed. McGraw-Hill, New York.

Steele, J . M. (1988). Growth rates of Euclidean minimal spanning trees with power weighted edges. Ann. Probab. 16 1767-1787.

WhitNey, V. K. M. (1972). Minimal spanning tree. Comm. ACM 15273.

Wu, F. Y. (1977). Number of spanning trees on a lattice. J. Phys. A 10 L113-L 115.

Department of Mathematics

YONSEI UNIVERSITY

134 SINCHONDONG

SEODAEMOONGU

SEOUL

REPUBLIC OF KOREA 120-749

E-MAIL: sungchul@bubble.yonsei.ac.kr 